\title{
Distraction Osteogenesis of the Maxillofacial Region
}

\author{
R. S. Neelakandan
}

\subsection{Introduction}

Reconstruction of the facial skeleton is a technique sensitive process for the reconstructive surgeon as the resulting outcome should improve the form and function of the patient. Distraction osteogenesis (DO) can be defined as the biologic process consisting of new bone formation between the bone segment surfaces that are gradually separated by incremental applied traction. It is a technique to which precludes donor site morbidity which is commonly performed to correct long bone deformities but gaining popularity in the maxillofacial reconstructive procedures in the recent times. The recent advancement of DO procedure is the transport distraction osteogenesis (TDO) which involves osteogenesis and histogenesis from the residual host tissues.

Following gradual movement of the transport segment, new bone regenerate formation occurs behind it filling the defect.

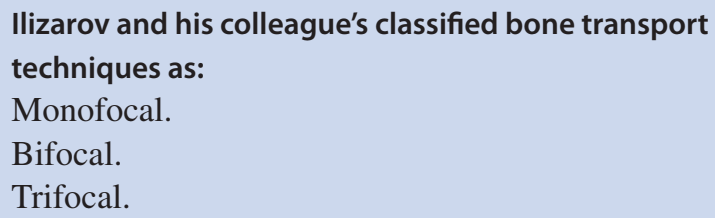

The bifocal and trifocal techniques play a major role in regenerating new bone across the continuity defects. TDO involves creating a new bone and soft tissue to cover the

Electronic Supplementary Material The online version of this chapter (https://doi.org/10.1007/978-981-15-1346-6_87) contains supplementary material, which is available to authorized users.

\section{R. S. Neelakandan $(\bowtie)$}

Department of Oral and Maxillofacial Surgery, Meenakshi Ammal Dental College and Hospital, MAHER, Chennai, Tamil Nadu, India defect by moving a segment of bone and new soft tissue formation behind it until the segment docks the receiving host bone. TDO can be achieved by movement of bone segments across the defect (Fig. 87.1a, b, and c).

\section{TDO is of three types:}

Bifocal.

Trifocal.

Quadrifocal.

Bifocal distraction is the incremental movement of one viable bone segment, trifocal distraction is the incremental movement of two viable bone segments and quadrifocal distraction is the incremental movement of three viable bone segments.

\subsection{History of DO}

Distraction osteogenesis (DO), a well-established technique used for several decades by orthopedic surgeons to repair long bone defects has over the past 15 years gained acceptance for correction of various craniofacial deformities. Bone distraction is not a new concept. Distraction was introduced first by Codvilla nearly a 100 years ago and was subsequently popularized during the 1940s by Ilizarov, who developed a single-stage procedure to lengthen long bones without the use of grafting material. The feasibility of applying Ilizarov's principles to different craniofacial deformities was not considered until several decades after his pioneering work in the peripheral skeleton. In the purest sense, the first reports of craniofacial DO were in the early 1960s, when rapid expansion of the palate was carried out in growing patients. This practice, however, involved distraction of a naturally occurring physis. Finally, in 1973, Snyder first described the Ilizarov technique to lengthen a surgical osteotomy of the 

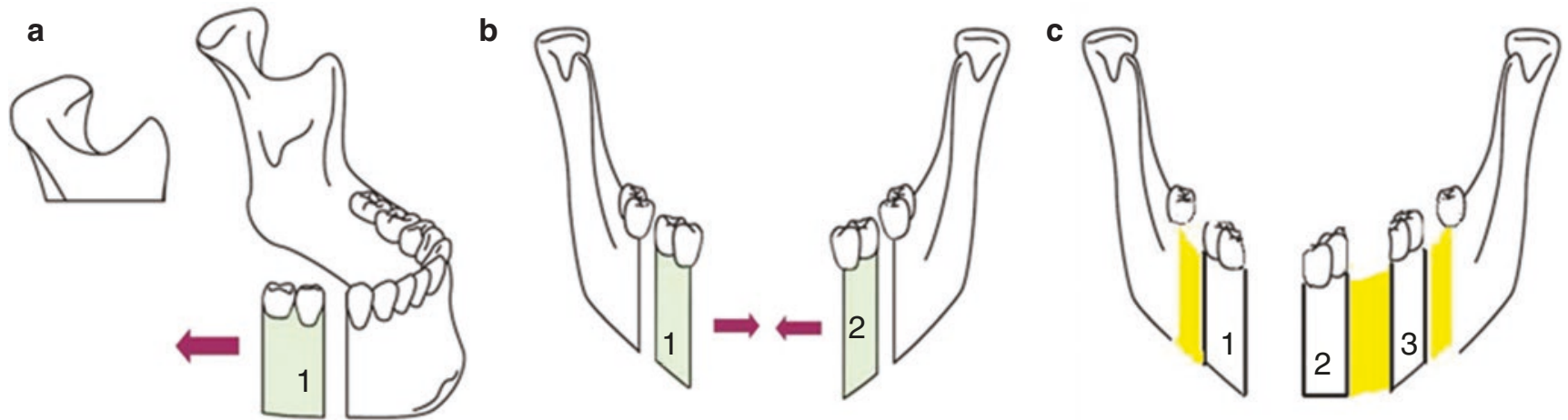

CAssociation of Oral and Maxillofacial Surgeons of India

Fig. 87.1 (a) Bifocal distraction, (b) Trifocal distraction, (c) Quadrifocal distraction

canine mandible. Interest in craniofacial distraction at first grew slowly, with sporadic experimental reports appearing over the ensuing two decades. However, in the early 1990s, experimental investigation intensified following reports from New York University on lengthening of dog mandibles and from Constantino and Friedman et al., who used DO to successfully close canine segmental lower jaw defects. Thereafter, several studies on various animal models demonstrated the application of osteodistraction at a number of different sites, including the mandible, midface, and cranial vault. It was Michieli and Miotti who first suggested the protocol for mandibular distraction in humans which included a latency period of 1 week after osteotomy followed by activation rate of $1 \mathrm{~mm}$ on alternate days and a minimum of 45 days consolidation period of every $15 \mathrm{~mm}$ distraction. In 1992, the first clinical results of craniofacial DO were reported by McCarthy et al. in a small series of patients with congenital mandible deformities. Since then, several larger series with longer follow-up periods have appeared. More recently, the technique has been successfully used for midfacial and upper craniofacial skeletal defects (Table 87.1) [1].

\subsection{Biology of Transport Distraction}

The adaptive function of bone to mechanical stimuli causing resorption of existing bone and formation of new bone is the continuous remodeling process of the bone tissue and was recognized as the Wolff's law. The principle behind DO is the application of defined mechanical strains to the reparative callus that is formed in the osteotomy gap. It is based on the law of tension stress by which states that gradual traction on living tissues creates stresses that can stimulate and maintain regeneration and active growth of these tissues.
Table 87.1 The history of DO is long and various researchers has contributed to its development, as summarized below

\begin{tabular}{|c|c|c|}
\hline 1728 & Fauchard & $\begin{array}{l}\text { Arch Expansion for accommodation of } \\
\text { crowd teeth }\end{array}$ \\
\hline 1828 & Wescott & Palatal arch expansion device \\
\hline 1893 & $\begin{array}{l}\text { Angel and } \\
\text { Goddard }\end{array}$ & Modified Wescott's device \\
\hline 1905 & Codivilla & Femur distraction \\
\hline 1927 & Rosenthal & $\begin{array}{l}\text { Intraoral tooth borne osteodistraction } \\
\text { device for mandible }\end{array}$ \\
\hline 1937 & Kazangian & $\begin{array}{l}\text { Over the face appliance and distracted } \\
\text { mandible using elastic traction }\end{array}$ \\
\hline 1948 & Crawford & $\begin{array}{l}\text { Demonstrated distraction force on a } \\
\text { fracture callus }\end{array}$ \\
\hline 1959 & Kole & $\begin{array}{l}\text { Used traction to correct anterior open } \\
\text { bite }\end{array}$ \\
\hline $\begin{array}{l}\text { Mid- } \\
\text { twentieth } \\
\text { century }\end{array}$ & Ilizarov & Long bone distraction \\
\hline 1973 & Synder et al. & $\begin{array}{l}\text { Distraction of membranous bone of } \\
\text { facial skeleton }\end{array}$ \\
\hline 1976 & $\begin{array}{l}\text { Michieli and } \\
\text { Miotti }\end{array}$ & $\begin{array}{l}\text { Developed mandibular distraction. } \\
\text { First suggested operative protocol for } \\
\text { human mandibular distraction protocol }\end{array}$ \\
\hline 1989,1992 & $\begin{array}{l}\text { McCarthy } \\
\text { et al. }\end{array}$ & $\begin{array}{l}\text { Used miniature orthopedic device for } \\
\text { small bone lengthening. } \\
\text { Reported first clinical case of } \\
\text { mandibular DO in humans }\end{array}$ \\
\hline 1990 & $\begin{array}{l}\text { Constantino } \\
\text { et al. }\end{array}$ & $\begin{array}{l}\text { Reported the first bifocal distraction } \\
\text { (TDO) of the mandible by using an } \\
\text { external custom made distraction } \\
\text { device }\end{array}$ \\
\hline 1997 & Fedotov & $\begin{array}{l}\text { Designed a semi-circular external } \\
\text { distractor, very similar to the present } \\
\text { day external distractors. } \\
\text { Designed monofocal, bifocal, and } \\
\text { trifocal distraction based on the size of } \\
\text { the defect to be reconstructed }\end{array}$ \\
\hline 1987 & Wolfson & $\begin{array}{l}\text { Designed the first intra oral } \\
\text { distractor-Considered as a landmark } \\
\text { in TDO } \\
\text { But was never used in patients }\end{array}$ \\
\hline
\end{tabular}


The sequence of DO is, osteotomy first, followed by latency period, which is the duration from bone division to the onset of traction. The third phase is the distraction phase which is the time when gradual traction is applied and distraction regenerate is formed, followed by the consolidation period which allows maturation and corticalization of the regenerate after traction forces are discontinued. The last

\section{Sequence of DO}

Osteotomy.

Latency period.

Distraction phase.

Consolidation period.

Remodeling phase.

stage is the remodeling phase where there is completion of the regenerated bone remodeling [1] (Fig. 87.2a, b).

The entire healing process of TDO is similar to that of a fracture healing process. The osteotomy causes discontinuity of the skeletal segment which triggers an evolutionary pro- cess of bone repair. It involves recruitment of osteoprogenitor cells, followed by cellular modulation or osteoinduction, and establishment of an environmental template or osteoconduction resulting in a reparative callus. The latency period is the period from bone division to the onset of traction. It represents the time allowed for reparative callus formation. On the fifth day after osteotomy, a mini-cellular network of growing capillary loops is formed in the medullary canal of both proximal and distal segments in the areas adjacent to the fracture line. This is a stage represented by soft callus where granulation tissue is converted to fibrous tissue by fibroblasts starting in the periphery.

During distraction phase traction force is applied to the bone segments and is slowly pulled apart, resulting in formation of new bony tissues which progressively increases the intersegmental gap. The cartilaginous callus is replaced by new bone formation due to various cellular activities, and this stage of hard callus remains for approximately 3-4 months. However, the normal fracture healing process is interrupted by the application of gradual traction to the soft callus. As distraction begins, the fibrous tissue of the soft callus becomes longitudinally oriented along the axis of distraction. In the second week of distraction, primary trabeculae
Fig. 87.2 (a, b) Traction force applied to the bone segments, slowly pulling them apart, resulting in formation of new bone. (c) Line diagram depicting process of TDO in a mandible requiring reconstruction for a segmental defect
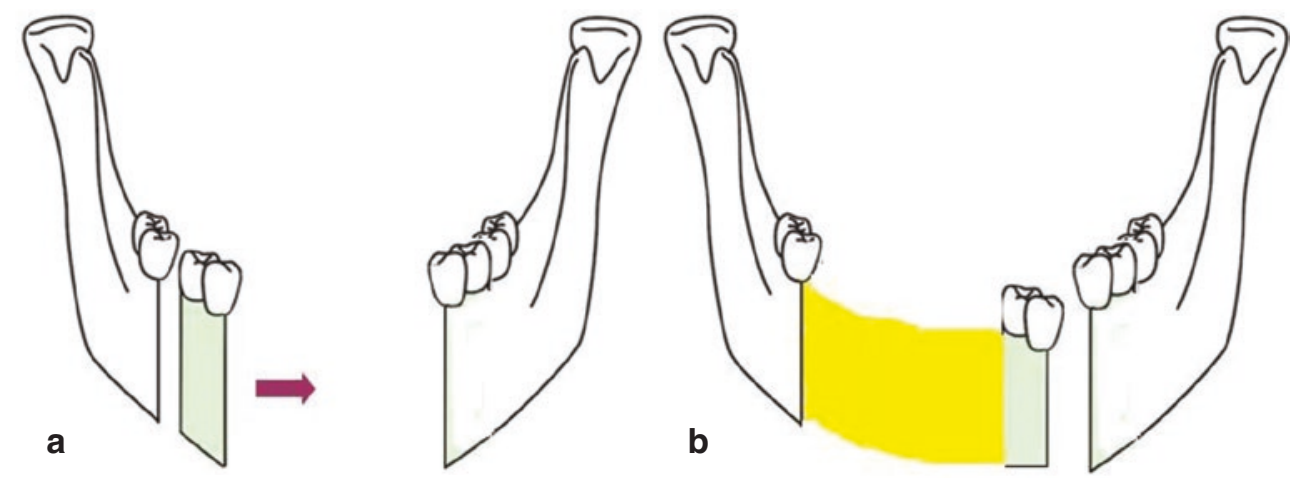
begin to form and the osteoid begins to mineralize. In TDO both membranous and endochondral processes play an important role in the process of new bone formation.

The consolidation period is defined as the time between cessation of traction forces to the removal of distraction device. It represents the time required for complete mineralization of the distraction regenerate. The remodeling period is the period from the application of full functional loading to the complete remodeling of the newly formed bone. The distraction regenerate is remodeled to mature bone during remodeling at a later stage.

\subsection{Biology of Bone Transport}

Biologically, bone transport techniques are based on two distinct processes, distraction osteogenesis and transformational osteogenesis. DO as previously described, is a biologic process of new bone formation between the surfaces of bone segments that are gradually separated by incremental traction. Transformational osteogenesis is a mechanically induced biologic process of pathologic bony tissue transformation into normal bone. Importantly, these two processes occur simultaneously during bifocal bone transport. Distraction osteogenesis occurs between the surfaces of the residual host bone segment and the trailing edge of the transport disc, while transformational osteogenesis occurs between the leading edge of the transport disc and the residual target bone segment (Figs. 87.3 and 87.4a, b).

In TDO the transport segments undergo stress due to compressive forces as well as distraction force. For instance, in bifocal transport, the leading edge realizes compression force, while the trailing edge realizes distraction force, and with trifocal transport, the leading edge of both segments realizes one common compressive force, and the trailing edge realizes two distraction forces one on either side.

\subsection{Device Design}

The concept of TDO has been increasingly applied to the craniofacial skeleton in the recent years. Initially used in experimental animal models, then gradually it gained popularity in the clinical setup. After encountering failures with avascularized and vascularized grafts in our patients with mandibular continuity defects, this modality of reconstruction was contemplated in our clinical practice. After treating 22 cases with earlier generation distraction devices, there were certain biological and mechanical problems resulting due to lack of vector control and inadequate tension stress effect. For these reasons various modifications were made in
Distraction Osteogenesis

Fibrocartilagenous Change

Transformational Osteogenesis

Compression Osteosynthesis

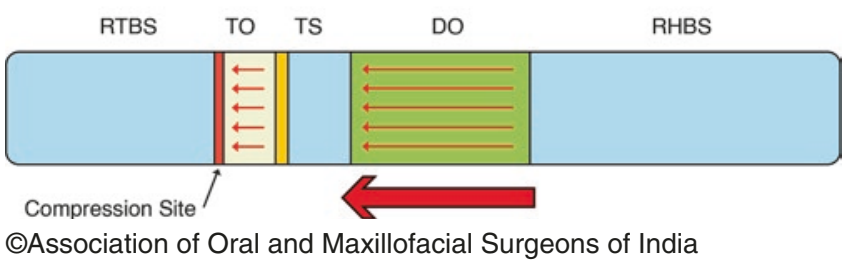

Fig. 87.3 Biology of bone transport. ( $D O$ distraction osteogenesis, RHBS residual host bone segment, TS transport segment (transport disc), RTBS residual target bone segment, TO transformational osteogenesis)

the initial design with an aim to improve the vector control and stability of the device.

The transport distraction device may be divided into three components:

- The reconstruction plate for stability.

- The distractor component for mobilizing the transport segment on activation.

- The screws for anchorage.

A proper surgical plan and device design should be followed in each case to achieve the desired results. Few factors that are to be considered are the cross-sectional dimension of the transport disc and the length of the defect along with number of teeth in the disc which can be used for prosthetic rehabilitation as well as to monitor the movement of transport disc during the distraction. It is essential to decide if the condyle should be retained or disarticulated to incorporate the condylar component in the device. It is advisable to retain the condyle when possible so as to maintain the natural joint architecture (Table 87.2 and Figs. 87.5, 87.6, 87.7, 87.8, 87.9 and 87.10).

\subsection{Biomechanical and Vector Consideration in Mandible and Selection of Device}

The success of distraction osteogenesis is based on biological and biomechanical factors. The biological factors are the length and geometric shape of the defect (straight unilateral posterior/curved across midline), cross-sectional area, and 
a
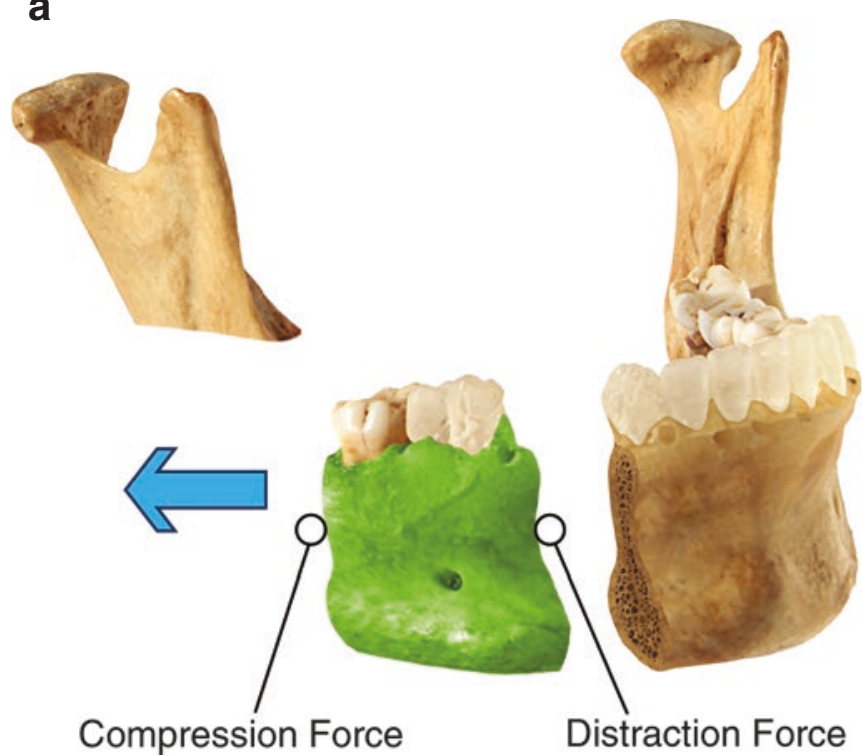

b

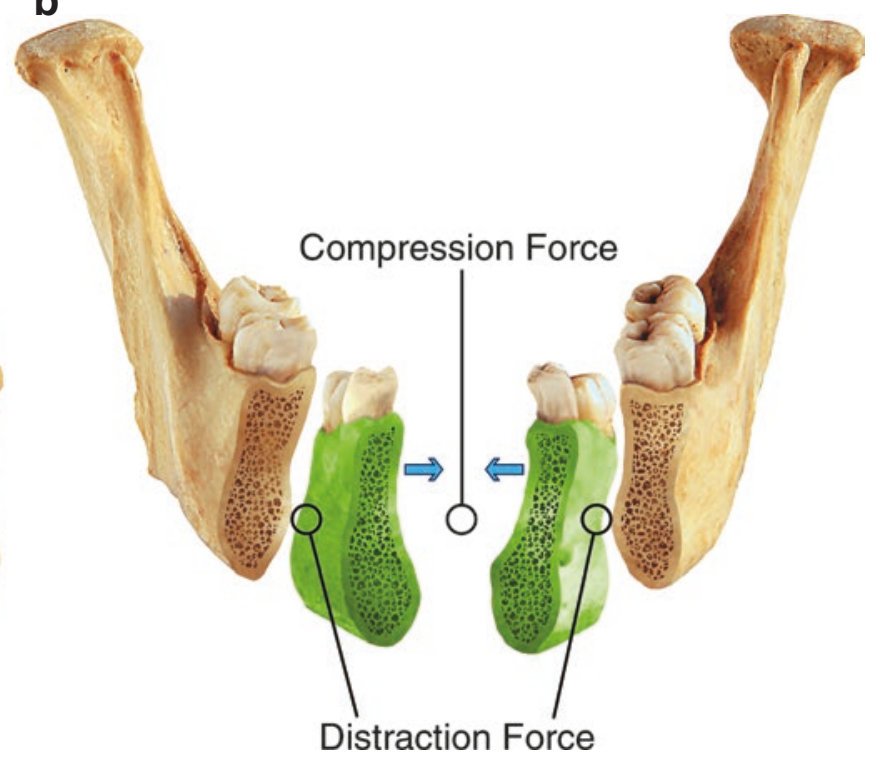

(C)Association of Oral and Maxillofacial Surgeons of India

Fig. 87.4 (a, b) Stress realized by transport segment in bifocal and trifocal distraction

Table 87.2 Generations of transport distraction devices, its merits, and demerits

\begin{tabular}{|c|c|c|c|}
\hline DO device & Design & Merits & Demerits \\
\hline $\begin{array}{l}\text { 1st generation } \\
\text { extraoral device } \\
\text { (Fig. } 87.5 \mathrm{a}, \mathrm{b}, \mathrm{c} \text {, } \\
\text { d, e) }\end{array}$ & $\begin{array}{l}\text { A single guidance rod with a single anchorage fixator } \\
\text { on either side of the cut ends of residual host bone } \\
\text { without a reconstruction plate to stabilize the cut ends } \\
\text { of the mandible }\end{array}$ & & $\begin{array}{l}\text { Unstable residual host bone with } \\
\text { inadequate control of the transport } \\
\text { segment producing sagittal deviations } \\
\text { Pin tract scarring }\end{array}$ \\
\hline $\begin{array}{l}\text { 2nd generation } \\
\text { (Fig. 87.6a, b, c) }\end{array}$ & $\begin{array}{l}\text { Reinforced with an additional guidance rod, and the } \\
\text { device is anchored to the residual host bone of either } \\
\text { side with double anchorage fixators } \\
\text { The cut ends of the bone are stabilized with a } \\
\text { reconstruction plate }\end{array}$ & $\begin{array}{l}\text { Better control of the } \\
\text { transport disc and } \\
\text { improved anchorage } \\
\text { Reduced incidence of } \\
\text { sagittal deviation }\end{array}$ & \\
\hline $\begin{array}{l}\text { 3rd generation } \\
\text { cantilever } \\
\text { distractor } \\
\text { (Fig. } 87.7 \mathrm{a}, \mathrm{b} \text { ) }\end{array}$ & $\begin{array}{l}\text { Used when there is no proximal bone available for } \\
\text { fixing the anchorage fixator } \\
\text { All the anchorage fixators are anchored to the available } \\
\text { bone, proximal to the transport segment }\end{array}$ & $\begin{array}{l}\text { Used when there is no } \\
\text { proximal bone available }\end{array}$ & \\
\hline $\begin{array}{l}\text { 4th generation } \\
\text { internal distractor } \\
\text { (Fig. } 87.8 \mathrm{a}, \mathrm{b}, \mathrm{c})\end{array}$ & $\begin{array}{l}\text { A straight device- and plate-guided internal distractor } \\
\text { with } 1 \mathrm{~mm} \text { calibrated guidance rod with a transport } \\
\text { device, attached directly to the reconstruction plate }\end{array}$ & $\begin{array}{l}\text { Better vector control } \\
\text { owing } \\
\text { Better patient compliance } \\
\text { No pin tract scar }\end{array}$ & $\begin{array}{l}\text { Can be used only for straight } \\
\text { regeneration }\end{array}$ \\
\hline $\begin{array}{l}5 \text { th generation } \\
\text { (Fig. 87.9a, b, c) }\end{array}$ & $\begin{array}{l}\text { An arched device consisting of a reconstruction plate } \\
\text { bent according to the contours of the defect and is } \\
\text { tissue buried to which a } 1 \mathrm{~mm} \text { calibrated arched } \\
\text { guidance rod is attached with a connecting vertical arm }\end{array}$ & $\begin{array}{l}\text { Completely placed } \\
\text { intraorally } \\
\text { Can be used to regenerate } \\
\text { bone across the midline } \\
\text { for central defects }\end{array}$ & \\
\hline $\begin{array}{l}\text { 6th generation } \\
\text { push ball device } \\
\text { (Fig. } 87.10 a, b)\end{array}$ & $\begin{array}{l}\text { Push ball device consists of a C-shaped cross-sectional } \\
\text { hollow guidance rod with the transport device } \\
\text { transfixed to the underlying transport segment that is } \\
\text { moved through a series of metal balls within the } \\
\text { guidance rod activated through a portal at the free end } \\
\text { of the rod }\end{array}$ & $\begin{array}{l}\text { It can be used for both } \\
\text { straight and curved defect }\end{array}$ & $\begin{array}{l}\text { Over-riding and clogging of the metal } \\
\text { balls can happen }\end{array}$ \\
\hline
\end{tabular}

density of the transport disc and tension of the soft tissue envelope. The biomechanical factors are dependent on the length and geometric shape of the defect that dictates the selection of straight or curved device.
Every vector is a one-dimensional entity, whereas the desired movements are in most cases two- or threedimensional. The base of the mandible is constituted by five linear vectors (Fig. 87.11). Two A-P linear vector running 
Fig. 87.5 (a) first generation extraoral device. $(\mathbf{b}, \mathbf{c})$ Panoramic radiographs showing the placed first generation distractor device. (d, e) Clinical pictures with the first generation device
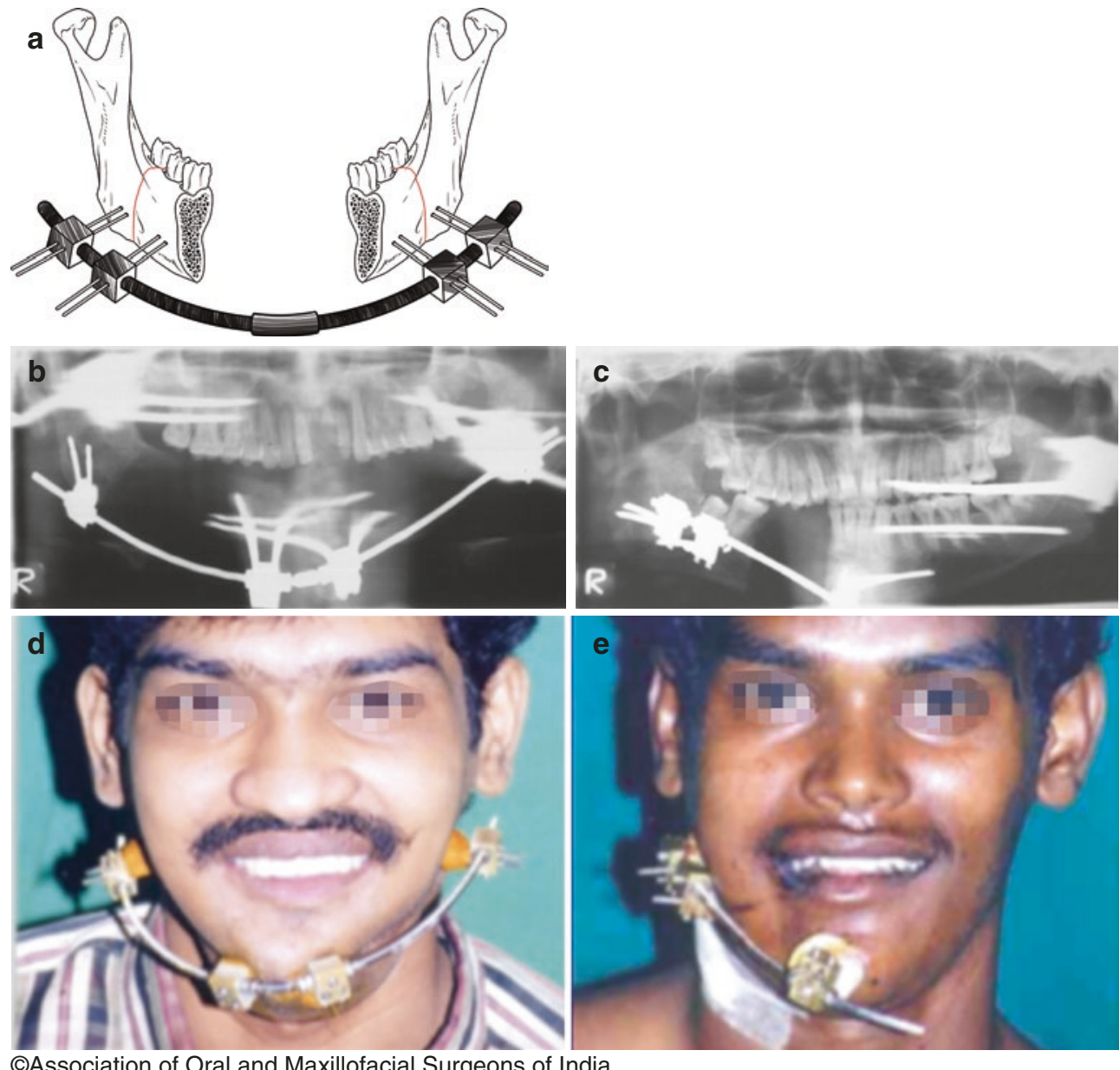

CAssociation of Oral and Maxillofacial Surgeons of India parallel to the base of the mandible one on either side in the body region, two A-P linear vector running parallel to the base of the mandible in the parasymphysis region, and one horizontal linear vector running again parallel to the base of the mandible in the mid symphysial region. If the defect is along a single vector, it is best reconstructed with straight regeneration, and if the defect is along more than single vector, it is best reconstructed with arched regeneration.

With the advent of various generations of devices for distraction osteogenesis, it is the author's contention that the straight tissue buried distraction device is preferred for unilateral defects, whereas, for bilateral defects crossing the midline, extraoral transcutaneous pin fixation device, either bifocal or trifocal is preferred, as it provides better vector control.

\subsection{Classification of Mandibular Defects in TDO}

Mandibular defects for reconstruction purpose are classified as central and lateral defects. Central defects can be either symmetrical or asymmetrical, and lateral defects can be either straight, when the defect is posterior to the second premolar and arched when the defect is from anterior to second premolar (Fig. 87.12a, b).

For reconstruction of central defects, when there is a symmetrical central defect, arched regeneration could be contemplated trifocally with identical transport segment from either side and when there is an asymmetrical central defect arched regeneration could be contemplated quadrifocally with nonidentical transport segments (Fig. 87.13). 

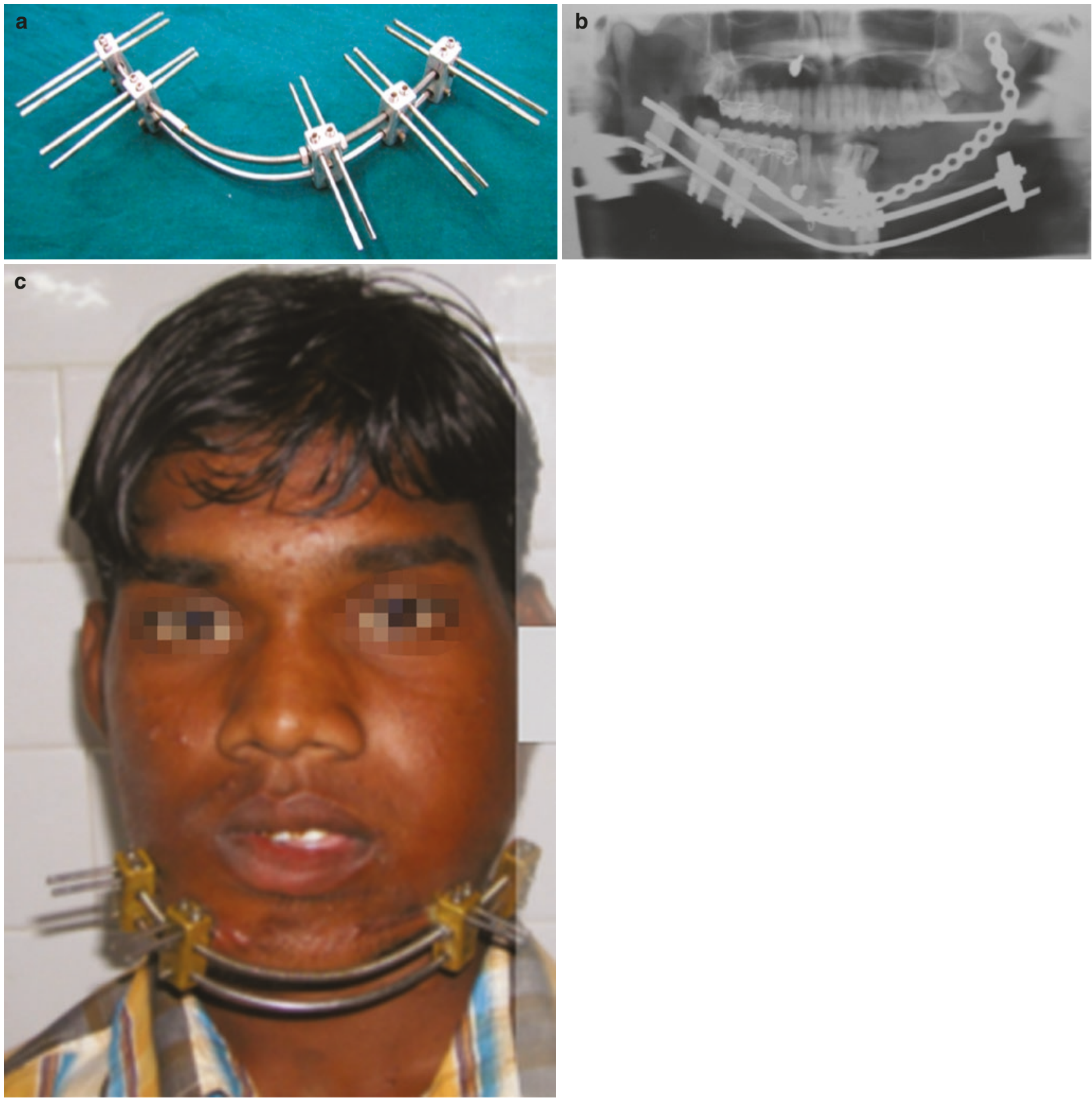

CAssociation of Oral and Maxillofacial Surgeons of India

Fig. 87.6 (a) second generation transport distraction device. (b) Panoramic radiograph showing placement of second generation device with a reconstruction plate. (c) Clinical picture showing second generation device 

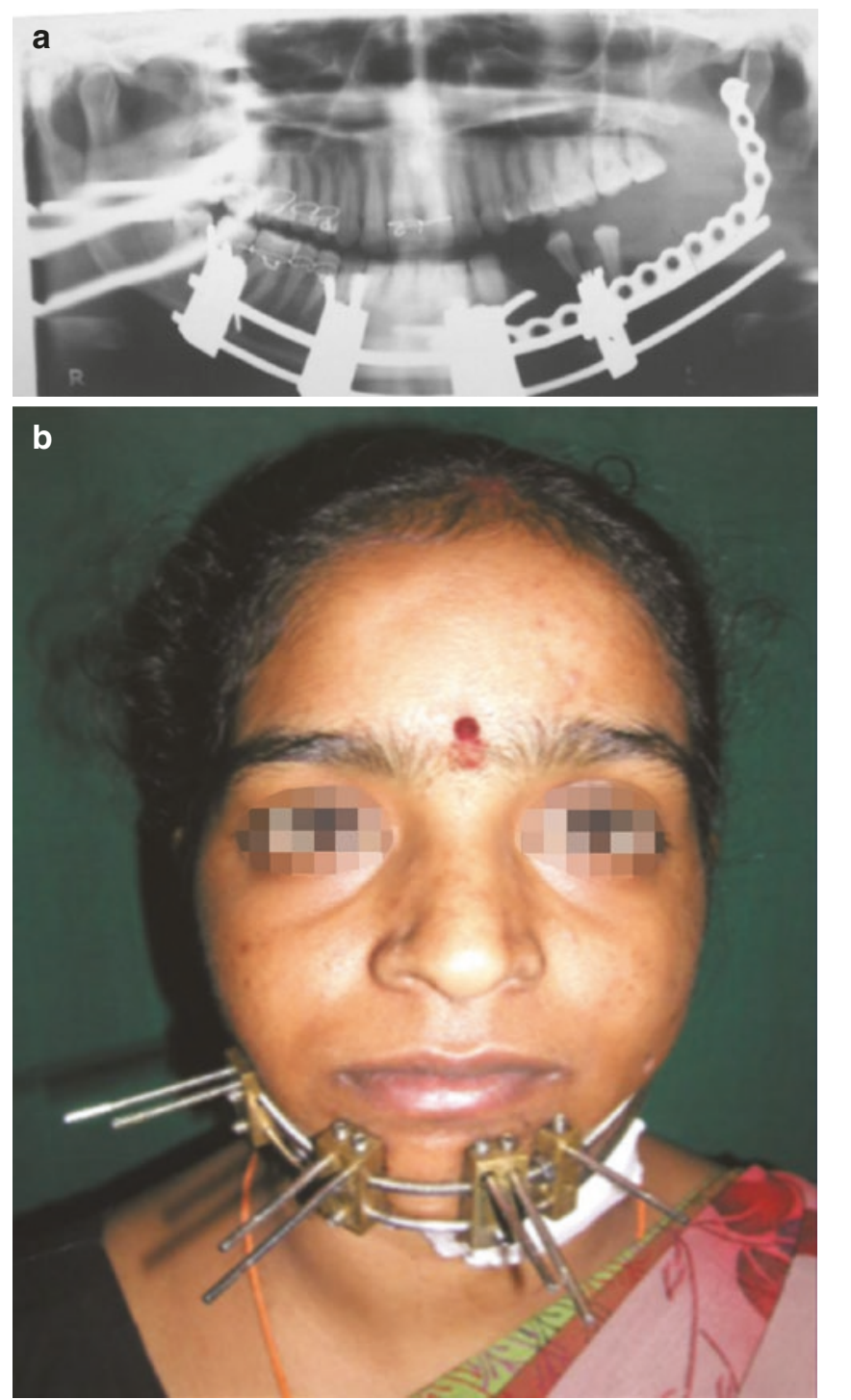

(C)Association of Oral and Maxillofacial Surgeons of India

Fig. 87.7 (a) Frontal profile view of patient with placement of third generation distractor device. (b) Panoramic radiograph showing the presence of third generation distractor device

When it comes to reconstruction of lateral defects, a single-vector defect posterior to the second premolar could be regenerated bifocally, and a two-vector defect anterior to canine could be regenerated either bifocally or trifocally depending upon the availability of horizontal ramus to create transport disc (Fig. 87.14a, b).

The choice of the transport distraction device is dependent upon the site of defect. For defects posterior to second premolar, a straight bar device with or without condylar prosthesis could be used and for defects anterior to first pre- molar an arched bar device across the midline could be used. However, a curvilinear push ball device could be used for both the types of defects.

\subsection{Indications of TDO}

Transport regeneration is indicated when there is a continuity defect of mandible due to any cause. It is indicated not only as a primary modality of reconstruction following tumor ablative surgery or bone loss due to trauma but also as a secondary modality of reconstruction whenever there is failure with previous reconstruction. It can also be carried out on pediatric patients and even on irradiated patients.

However, it has a limitation when there are no horizontal rami available on either side to create transport segment. Even in such situation, bone grafting and subsequent transportation can be contemplated.

\subsection{Presurgical Investigations}

When it comes to investigations, panoramic radiograph and CT will help us to know the exact extension of the lesion and thereby to assume the type of defect we are dealing with. This helps in selection of device.

Stereolithographic 3D models help us in contouring the device exactly along the defect presurgically. This helps in minimizing the working time on the table (Fig. 87.15a, b, $\mathrm{c}, \mathrm{d})$.

\subsection{Surgical Procedure}

Transport distraction involves creating a transport disc in the residual host bone stump, adjacent to a discontinuity defect or a resection site. The transport disk is then advanced $1.0 \mathrm{~mm}$ per day to span the discontinuity defect. As this transport disc advances toward the target host bone segment, callus forms at its trailing edge, which gradually matures and calcifies. Once the transport disc reaches the docking site, the segment is held in neutral fixation until a cortical outline is seen in the regenerate. At the time of distractor removal, a small bone graft may need to be positioned between the transport disc and the docking site because the transport disc becomes rounded and encased with a fibrocartilaginous cap on the advancing front. Osseous union between the disc and docking site necessitates removal of this intervening fibrocartilaginous cap. 

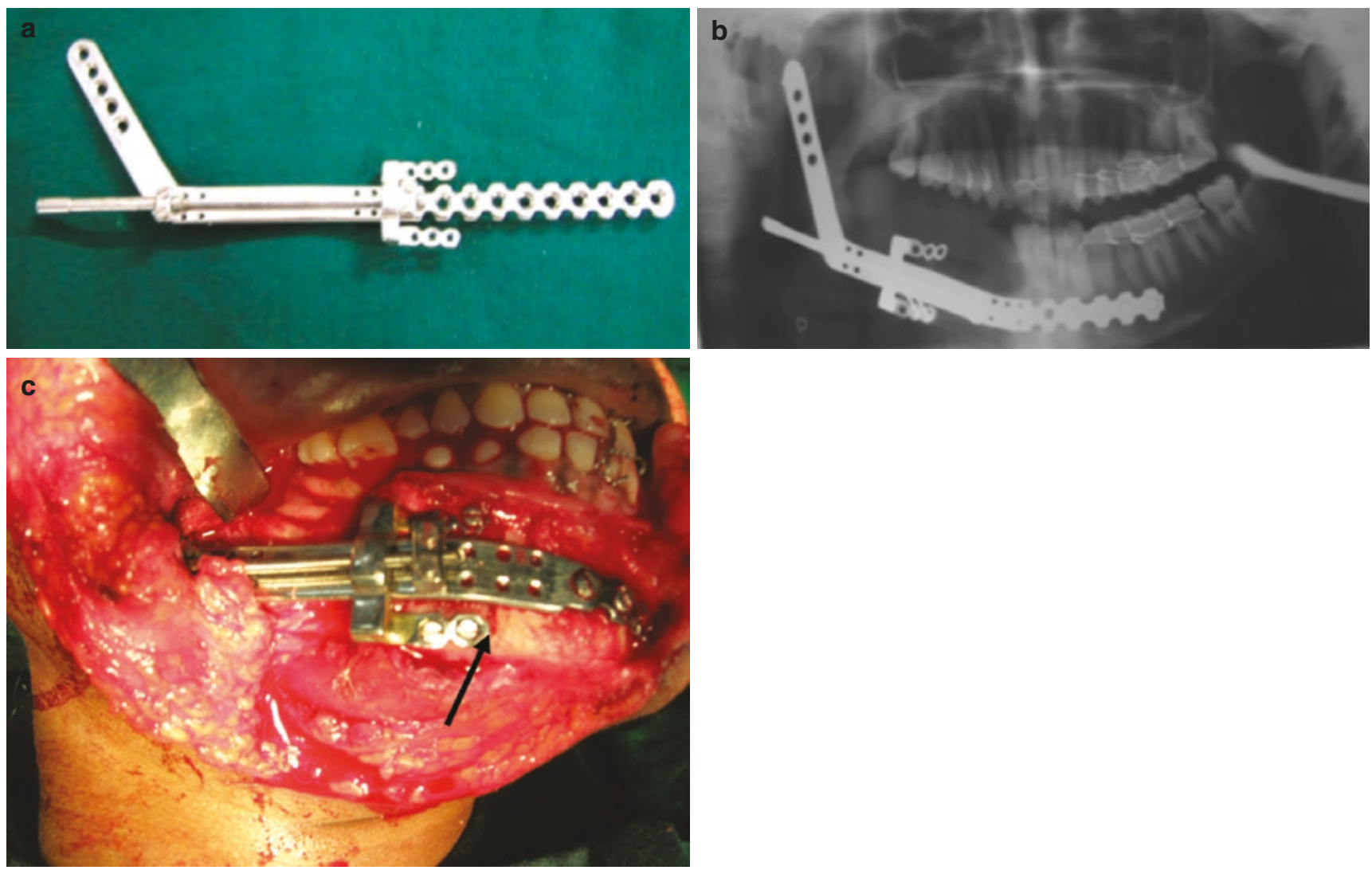

CAssociation of Oral and Maxillofacial Surgeons of India

Fig. 87.8 (a) fourth generation distractor device with an attached reconstruction plate. (b) Panoramic view showing presence of fourth generation device without a condylar component. (c) Placement of the device in the mandible after a lip split incision
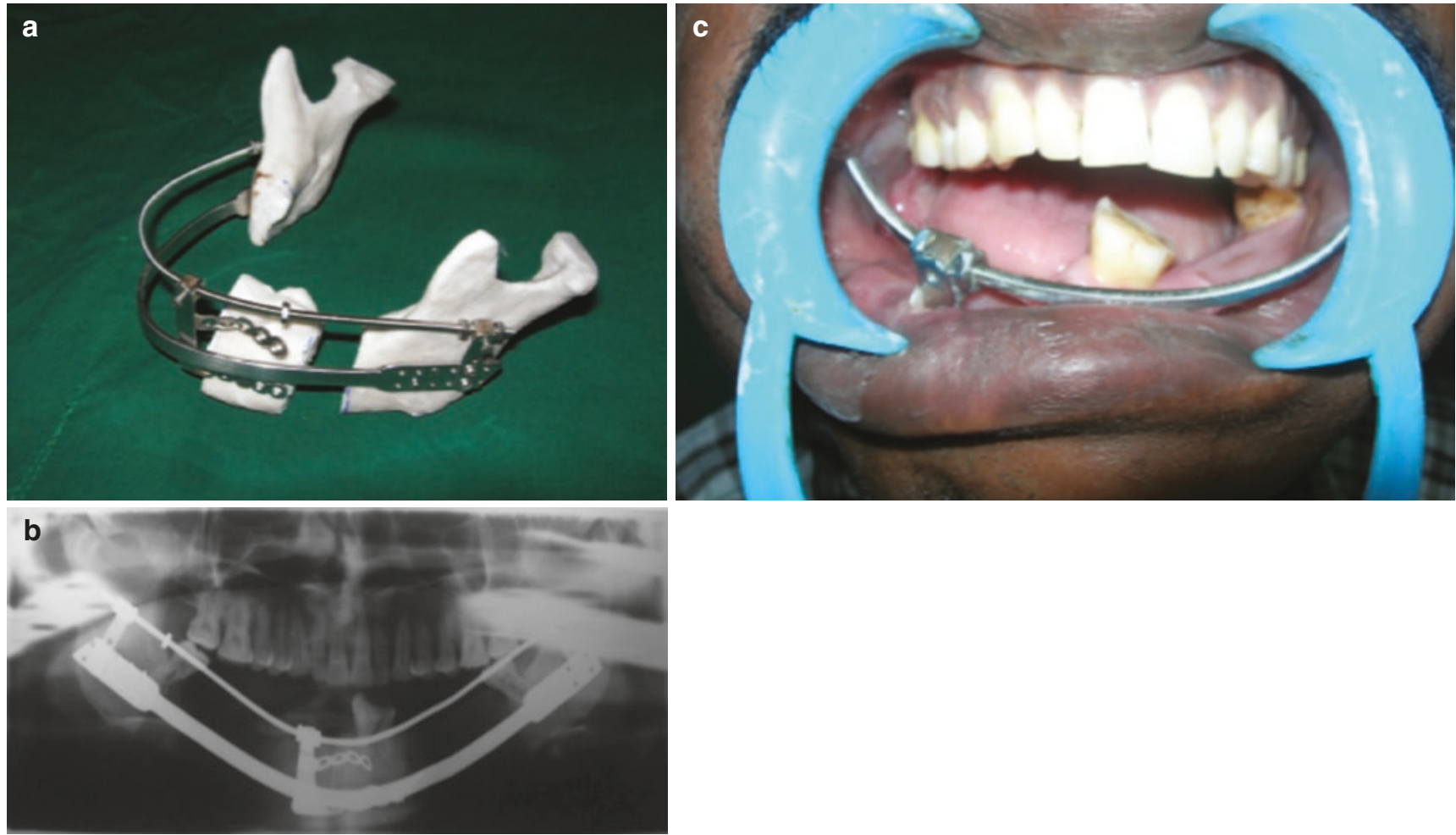

CAssociation of Oral and Maxillofacial Surgeons of India

Fig. 87.9 (a) fifth generation arc-shaped device, adapted on STL model. (b) Panoramic radiograph showing the placement of fifth generation device. (c) Clinical picture of fifth generation device 

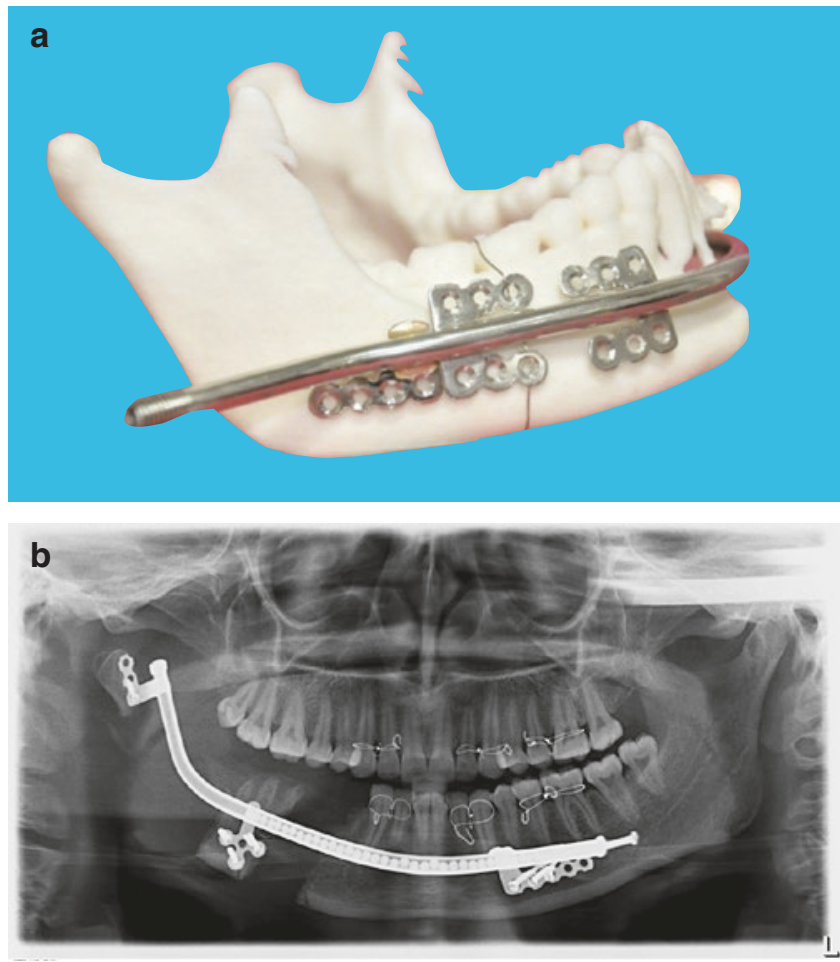

CAssociation of Oral and Maxillofacial Surgeons of India

Fig. 87.10 (a, b) Curvilinear ball device for straight and arched regeneration

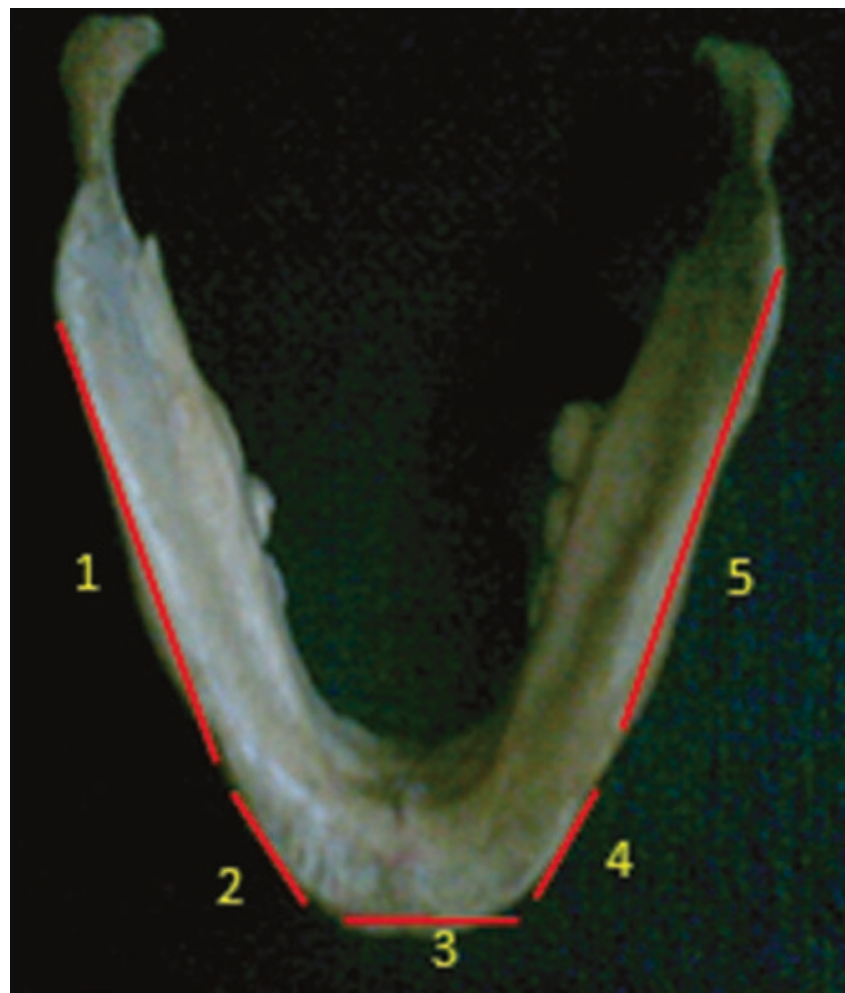

CAssociation of Oral and Maxillofacial Surgeons of India

Fig. 87.11 Linear vectors in mandibular reconstruction

\subsection{Biological Consideration While Designing Transport Disc}

Periosteal preservation is the single most important biologic consideration while designing bone transport, for the transport segment solely depends on periosteal blood supply for its viability. Hence extreme care at every stage_right from making a small incision to minimal periosteal reflection to abundant irrigation and water tight mucosal closure over the transport segment-should be ensured.

While designing the transport segment, parallelism of the cut edges of the residual host bone segment, transport segment, and target bone segment should be ensured to achieve even docking of the transport disc to the cut edges of residual target bone segment. This is carried out by taking the vertical osteotomy cut perpendicular to an imaginary baseline that runs between gonion and menton and parallel to maxillary occlusal plane (Fig. 87.16a-e) followed by implant rehabilitation (Figs. 87.17 and 87.18).

\subsection{Vascular, Clinical, Radiological, and Histological Features of the Regenerated Bone}

The process of TDO induces tensile stretching of the osteoblast-like cells that alters the local regulation of bone formation and increases the expression of the growth factors. This entire process is vascular-dependent and requires the maintenance of an adequate blood supply. DeCoster et al. in their animal experimental model on transport distraction osteogenesis used injection angiography to study the arterial response of the bone undergoing transport distraction. The angiographic techniques revealed that the transport segment had an intact arterial supply after the osteotomy cut was completed (adhering to surgical principles of TDO) and, also, after transport distraction was activated. They also showed an extensive increase in vessels in distracted limbs of the experimental animals with proximal stretching and distal kinking of the major artery in that limb. Such studies involving major facial vessels during TDO are awaited to be added to maxillofacial literature [2]. Formation of callus can be detected earliest with ultrasonography where it appears as a mixed to hyper echoic area depending upon the degree of maturation. The color Doppler study of the callus demonstrates the quantum of vascularity in the regenerate before maturation [1, 2] (Fig. 87.19).

For radiological examination (Figs. 87.20 and 87.21) regular plain film radiographs remain the mainstay for screening the TDO during active distraction and consolidation period. Panoramic radiograph, submento-vertex view, lateral oblique mandibular projections, and posteroanterior and lateral skull views may all aid in planning and screening the 
Fig. 87.12 (a) Defect posterior to second premolar, straight vector; defect anterior to second premolar, arched vector. (b) Classification of mandibular defects a

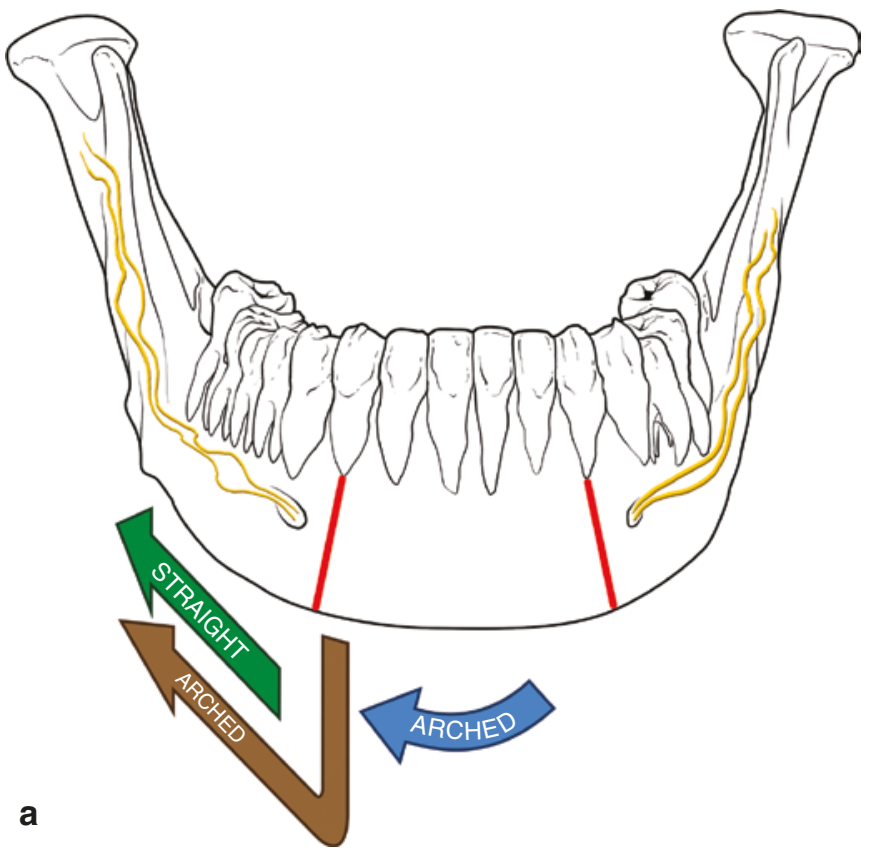

CENTRAL

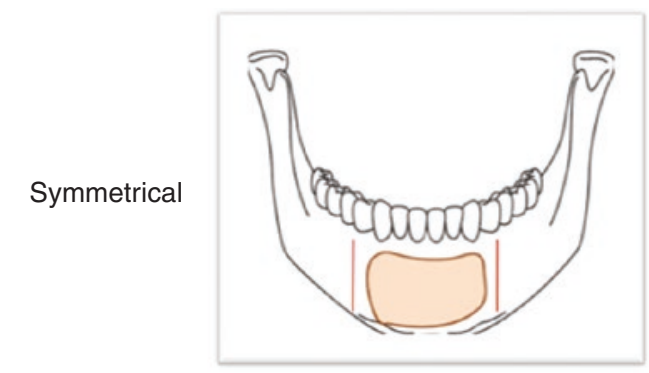

b

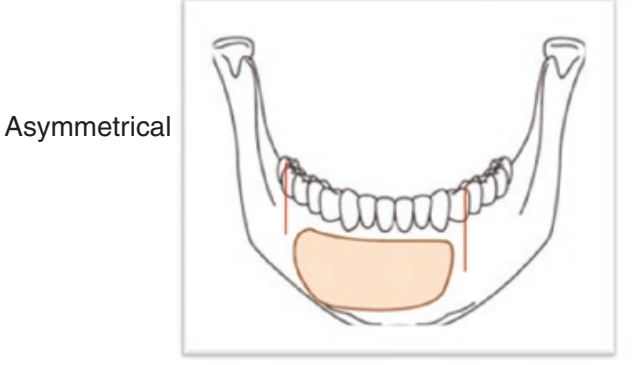

CAssociation of Oral and Maxillofacial Surgeons of India
LATERAL

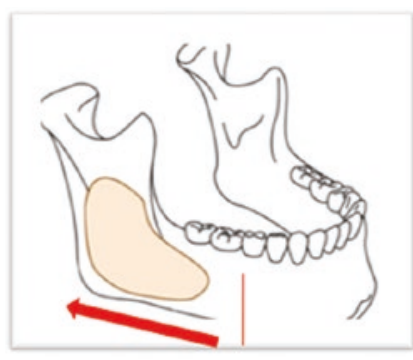

Straight

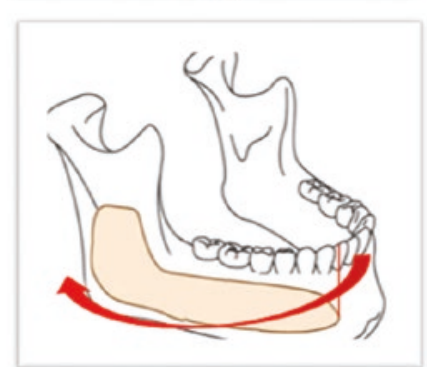

Arched
Symmetrical Defect

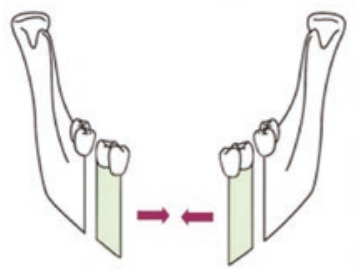

Trifocally with Identical Transport Discs (CAssociation of Oral and Maxillofacial Surgeons of India
Fig. 87.13 Reconstruction of central defects 
Fig. 87.14 (a, b)

Reconstruction of lateral defects
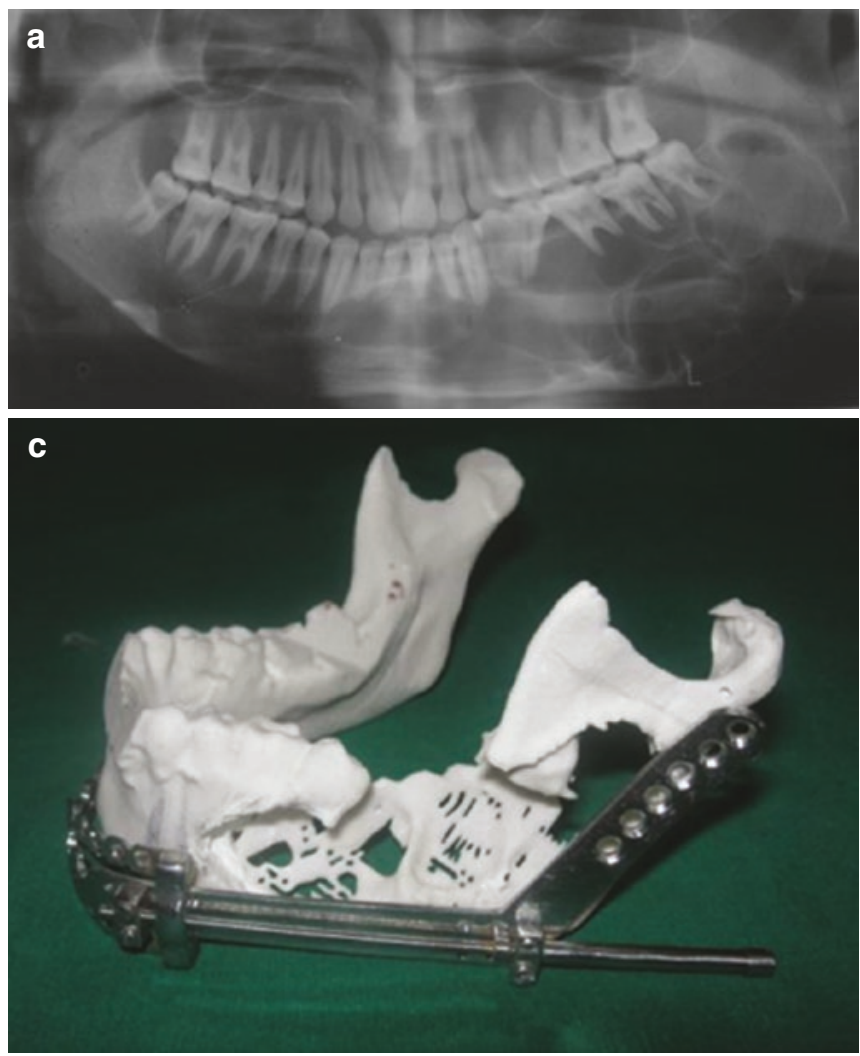

Bifocal Straight Regeneration

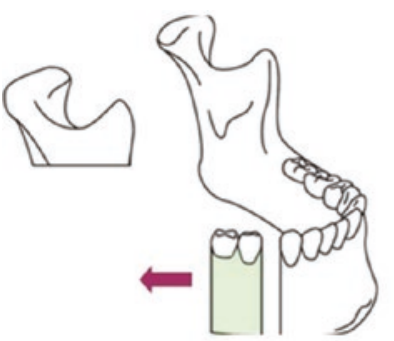

C

b Two Vector Defect

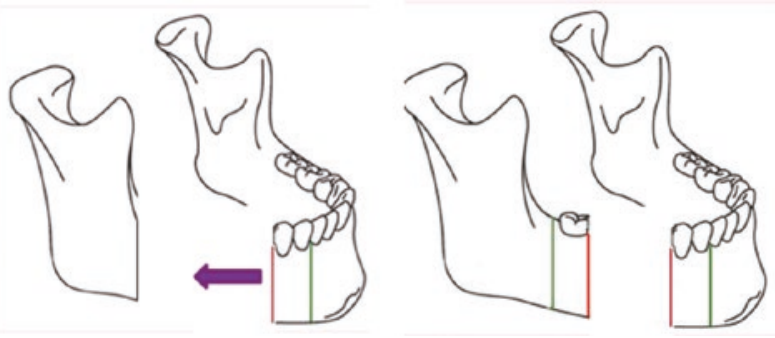

Bifocal/trifocal Arched Regeneration

\section{CAssociation of Oral and Maxillofacial Surgeons of India}

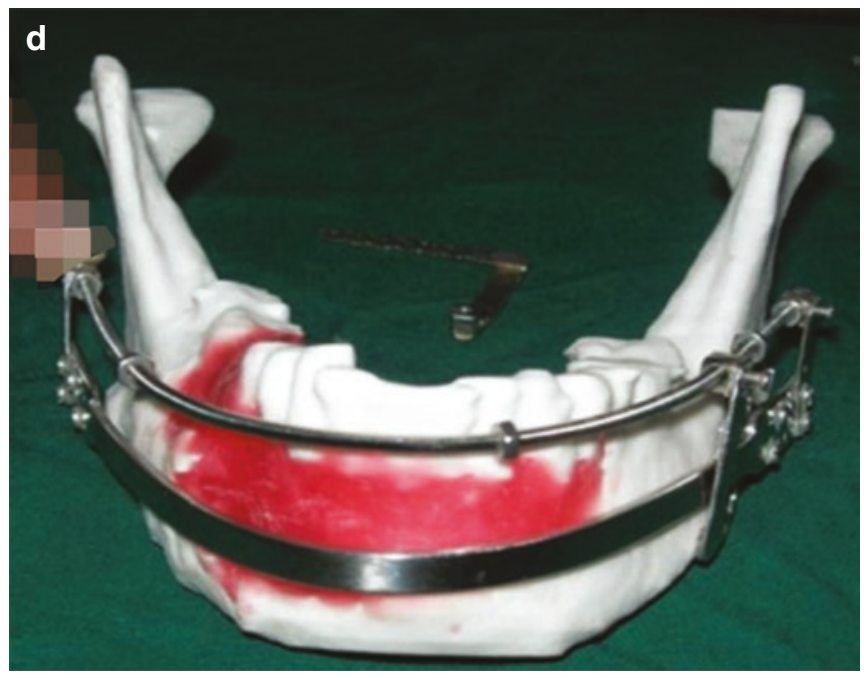

CAssociation of Oral and Maxillofacial Surgeons of India

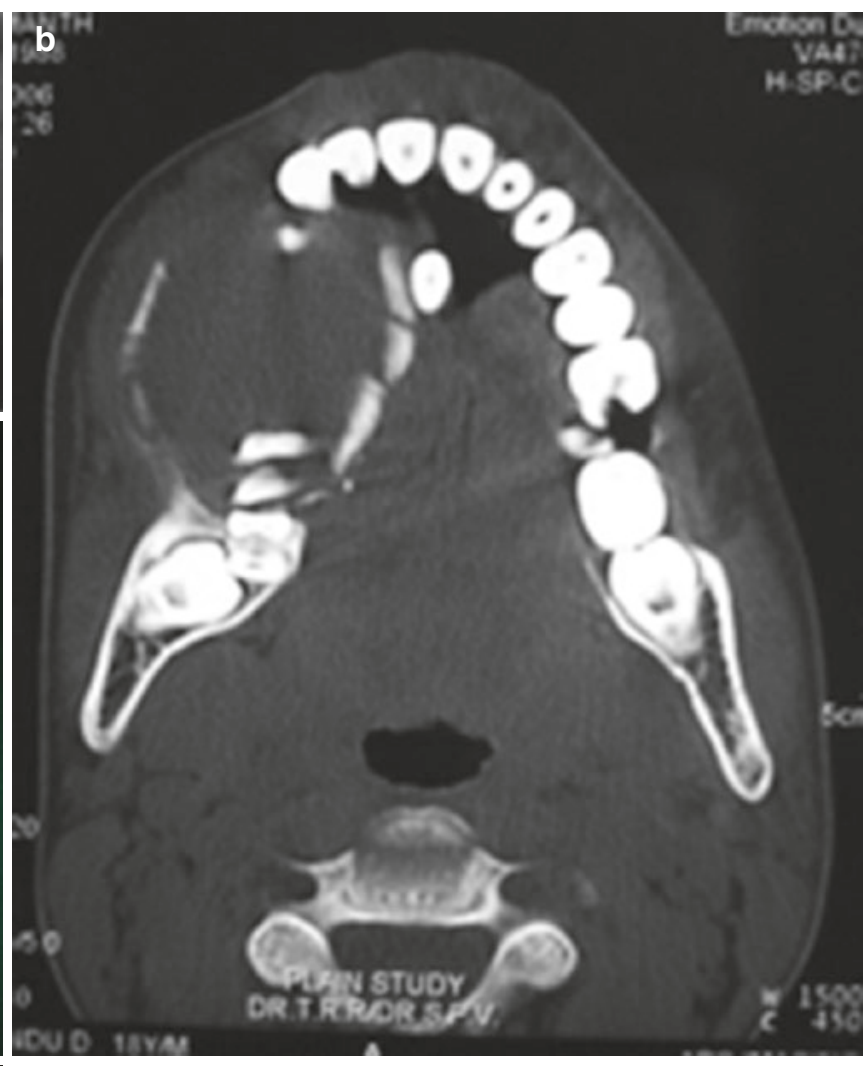

Fig. 87.15 (a, b, c, d) Presurgical planning 

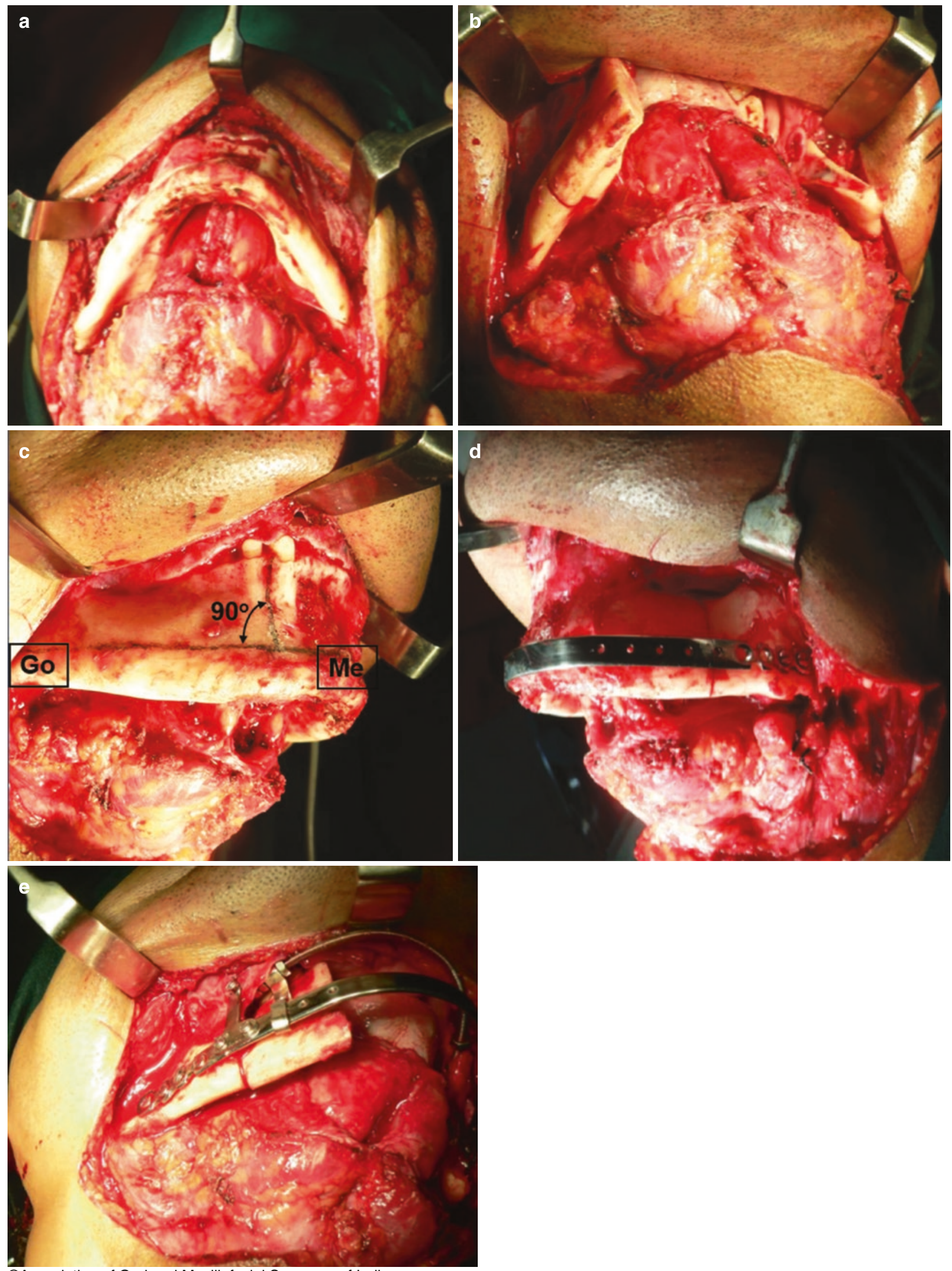

(c)Association of Oral and Maxillofacial Surgeons of India

Fig. 87.16 (a) Incision extending bilaterally to expose the entire mandible inferiorly after layered dissection. (b) The lesion resected with clear margins of the preserved bone. The osteotomy should be kept par- allel and free from the lesion. (c) Osteotomy cut perpendicular to an imaginary baseline that runs between Go and Me and parallel to maxillary occlusal plane. $(\mathbf{d}, \mathbf{e})$ Placement of fifth generation distractor 


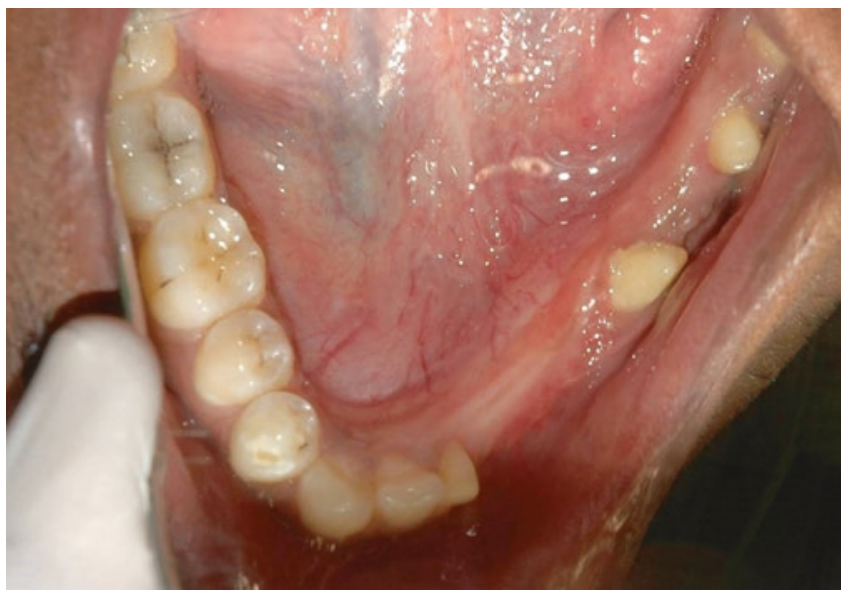

CAssociation of Oral and Maxillofacial Surgeons of India

Fig. 87.17 Clinical appearance of regenerate of patient from Fig. 87.16

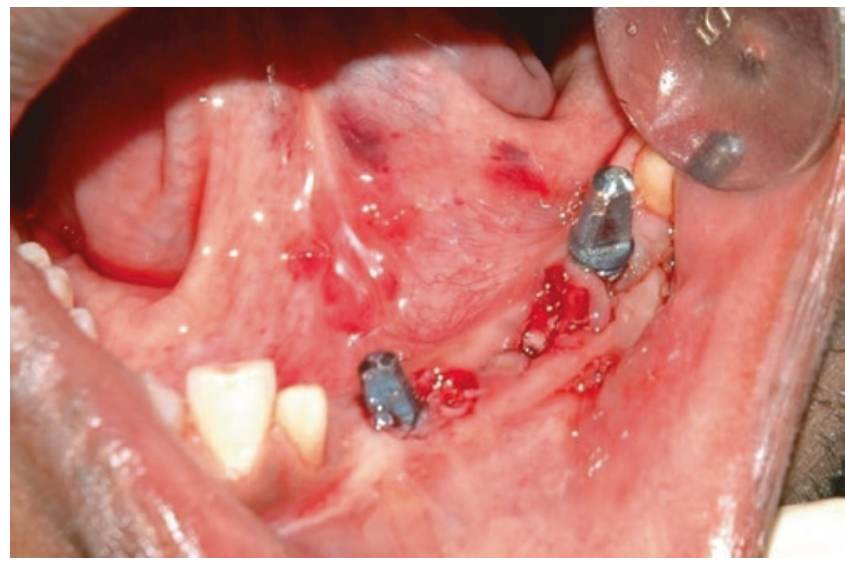

CAssociation of Oral and Maxillofacial Surgeons of India

Fig. 87.18 Implants placed on the regenerated bone after 1 year of the same patient from Fig. 87.16

TDO. These radiographs have their limitation of $2 \mathrm{D}$ view of the mutivectorial 3D procedure.

Multi-slice-computed tomographic scans provide a better preview but have the limitation of excessive radiation exposure and scatter due to the distraction device when it is in situ. Elsalanty et al. have extensively experimented on conebeam CT densitometry and three-dimensional histomorphometry in mandibular bone defects reconstructed with bone transport and found that the physical dimensions and architectural parameters of the new bone regenerated remain comparable to the contralateral normal bone in TDO [3]. In their study, the radiographic density comparison was done

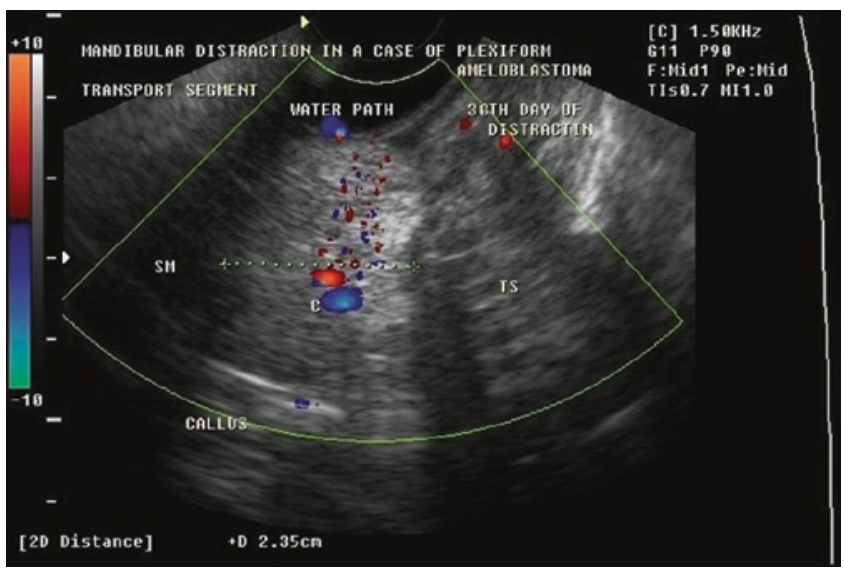

CAssociation of Oral and Maxillofacial Surgeons of India

Fig. 87.19 Ultrasound appearance of regenerate

by studying the radiographic attenuation of the regenerate measuring in Hounsfield units (HU) and comparing it to the outer, inner, and inferior cortices of the bone on opposite side of the mandible (normal bone). Their results showed that the density of the distraction regenerate was comparable to the inner and outer cortices of the control bone, whereas the lower border of the control side of the mandible showed higher density than the regenerate at 1 month of consolidation. The Hounsfield unit value of the regenerate by TDO was toward the 2000 mark (2000 HU) after a month of consolidation. Microcomputed tomography-based threedimensional histomorphometry used to assess percentage of bone volume, bone mineral density, degree of anisotropy, trabecular thickness, trabecular number, trabecular pattern factor, and trabecular separation showed no significant differences between the regenerate and the normal bone after a month of consolidation in all parameters except percent bone volume and the trabecular separation. Percentage bone volume is reported to be significantly less, while trabecular separation is significantly higher in the regenerate (Fig. 87.22a, b).

Garcia et al. studied the histology of the regenerate and docking site in bone transport in the tibial-diaphyseal defect of adult sheep model and concluded that there is a marked difference between the ossification of the docking site and of the regenerate. Intramembranous ossification plays a major role in the regenerate, with bone forming from the host bone segment to the target segment. The ossification of the docking site shows endochondral and intramembranous ossification simultaneously, but the intramembranous ossification is limited to rare and small foci [4]. 
Fig. 87.20 Radiological appearance of regenerate during active distraction

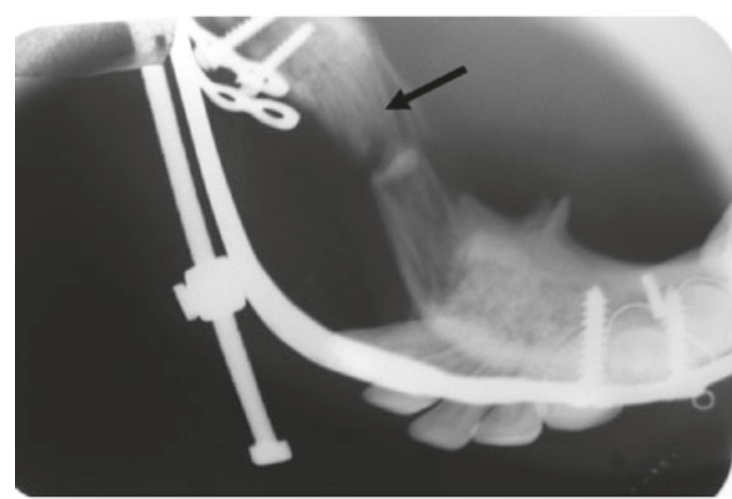

Radiolucent Interzone - fibroblastic activity

CAssociation of Oral and Maxillofacial Surgeons of India

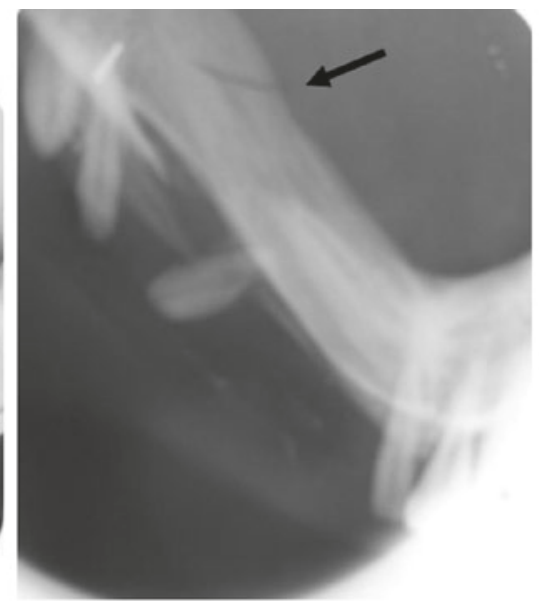

:ollagen parallel to vector of distraction

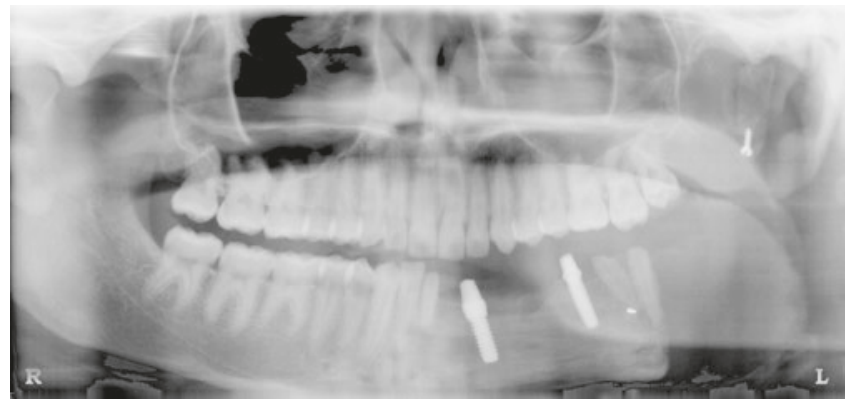

CAssociation of Oral and Maxillofacial Surgeons of India

Fig. 87.21 Osseointegrated dental implants in the regenerated bone

Fig. $87.22(a, b)$ CT appearance of regenerate
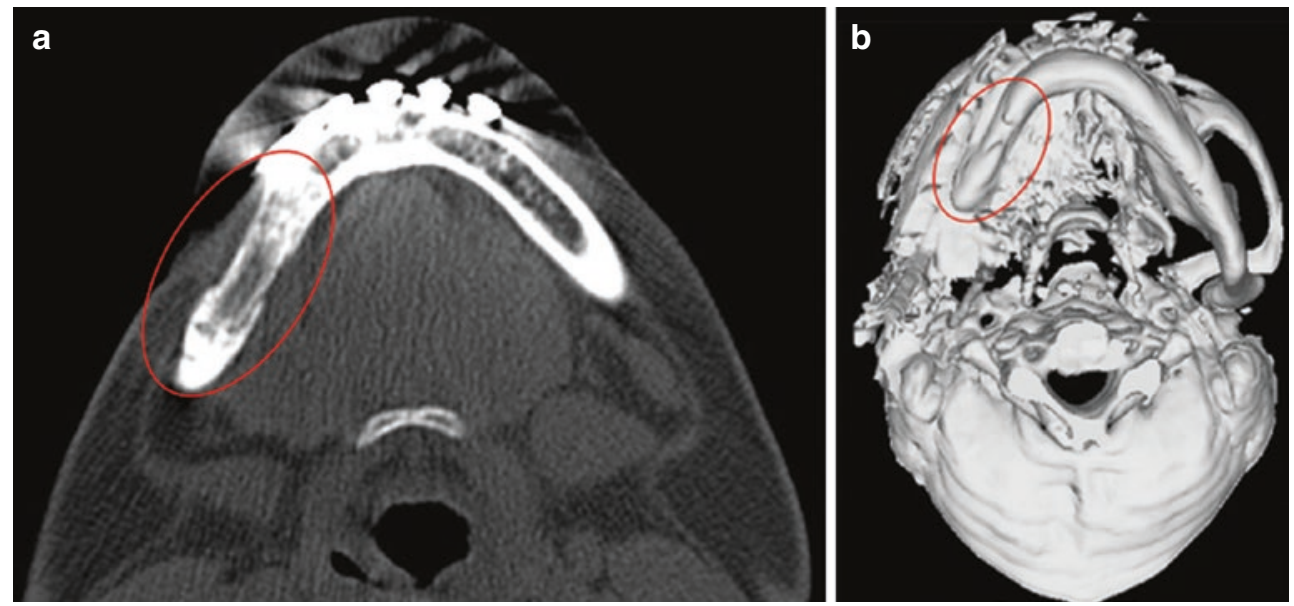

CAssociation of Oral and Maxillofacial Surgeons of India 
Studies done on the architecture and microstructure of cortical bone regenerated with TDO, it has been found that at 12 weeks of consolidation, bone created during bone transport distraction osteogenesis was comparable to native bone in microstructure, architecture, and mechanical properties, and when appropriate time has lapsed, the properties of the regenerate bone were identical to the host bone.

Çakır-Özkan et al. in their study on immunohistochemical analysis of reconstructed sheep mandibles by transport distraction osteogenesis reported strong positive staining for BMP-2, -4, and TGF- $\beta$ in the cells, and matrix components. These growth factors are believed to enhance the osteogenesis in TDO [5].

\subsection{Transport Distraction Osteogenesis in Maxilla}

Ever since the concept of transport distraction on long bone was initiated by Ilizarov and then after it was subsequently introduced on the facial skeleton by Constantino, Fodotov, Wolford, and many others, a lot of articles got published in the world literature affirming the possibility of regenerating quality bone for any length of mandibular defects [6]. It has even become a gold standard in comparison to other modalities of reconstruction. So, the question arises whether transport distraction has a role in maxillary reconstruction. $[7,8]$

Cheung et al. were the first to publish their work on reconstruction of a maxillectomy defect using transport DO in animal experimental model [9]. Our contention is that when transport distraction has become an accepted norm in the reconstruction of mandibular continuity defects, maxilla with its multiple vascular perfusion, rich periosteal supply, and increased cancellous bone is expected to biologically respond even better to the distraction force [10].

Here are a few cases showing our evolution in transport distraction osteogenesis for reconstruction of maxillary defects.

In our maiden clinical attempt at reconstructing a maxillary defect using TDO a straight distraction device was used. The limitation we had with straight bar device was that they were all buccally directed and not conforming to the posterior maxillary arch (Fig. 87.23a, b, c, d, e, f). Subsequently we have successfully employed bifocal transport distraction (Fig. 87.24a, b, c, d, e, f, g, h, i) and trifocal transport distraction (Fig. 87.25a, b, c, d, e, f, g, h) for reconstruction of maxillary defects. Maxillary TDO has also been successful to treat alveolar clefts of maxilla (Fig. 87.26a, b, c, d, e, f, g).

\subsection{Advantages of TDO}

Though bone transport may not be possible in all situations, when indicated, it has an edge over other modalities for it doesn't require any specialized hands or equipment, it doesn't prolong the duration of surgery and hence is costeffective. Since no bone grafting is required, there is no donor site morbidity, and there is recreation of alveolar ridge with attached mucosa, buccal, and lingual sulci, all in near normal anatomy. TDO not only regenerates new bone but also every element of soft tissue around it as well. These are summarized in Table 87.2.

\subsection{Complications of Bone Transport}

The complications with bone transport in regenerating new bone formation can be discussed under biological and mechanical factors. 

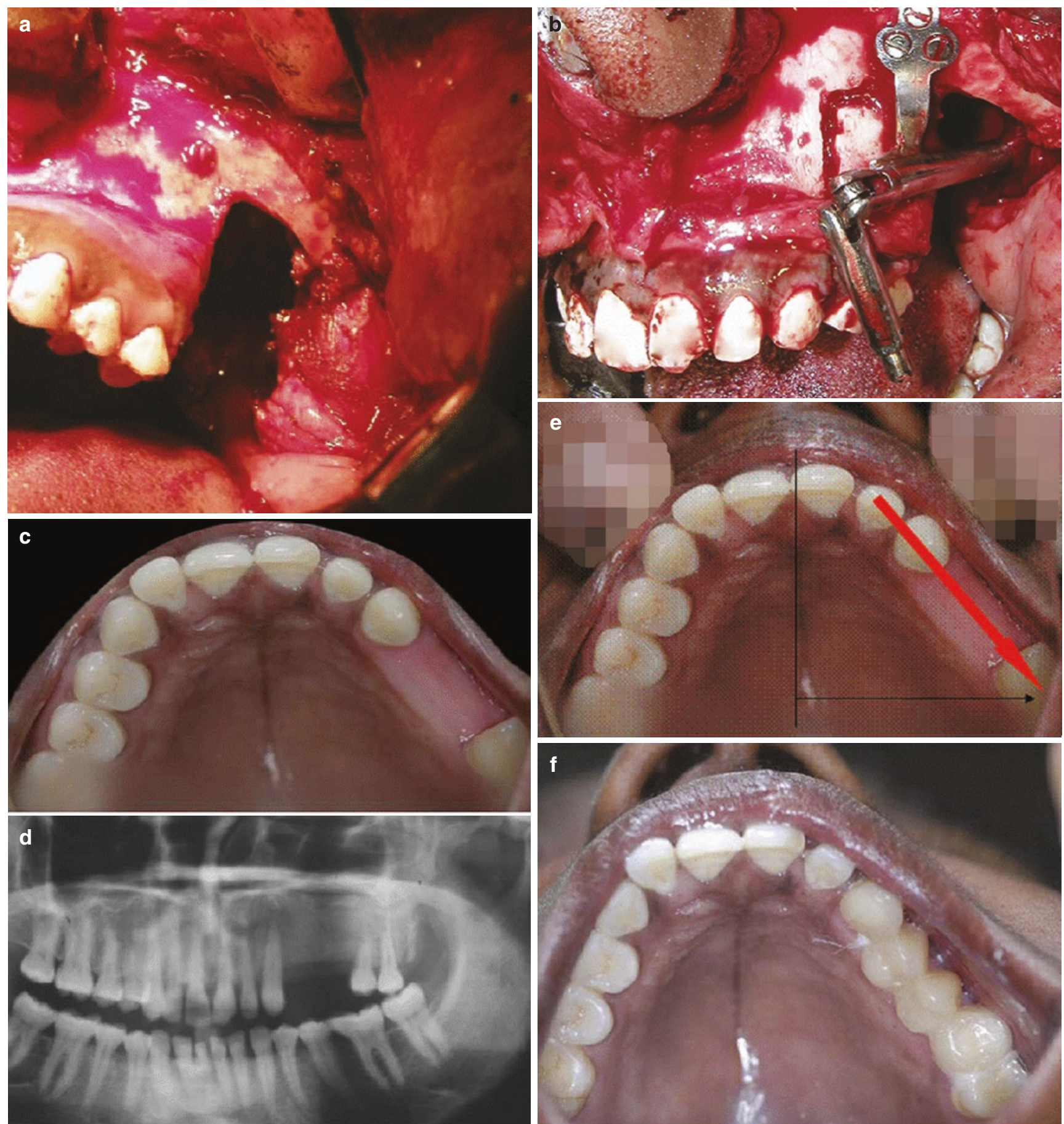

CAssociation of Oral and Maxillofacial Surgeons of India

Fig. 87.23 (a) Straight transport distraction device post-resection defect. (b) Transport disc with device. (c, d) Evidence of histogenesis

solidation phase. (e) Buccal deviation of the regenerate. (f) and osteogenesis in the clinical picture and OPG respectively, after con- 

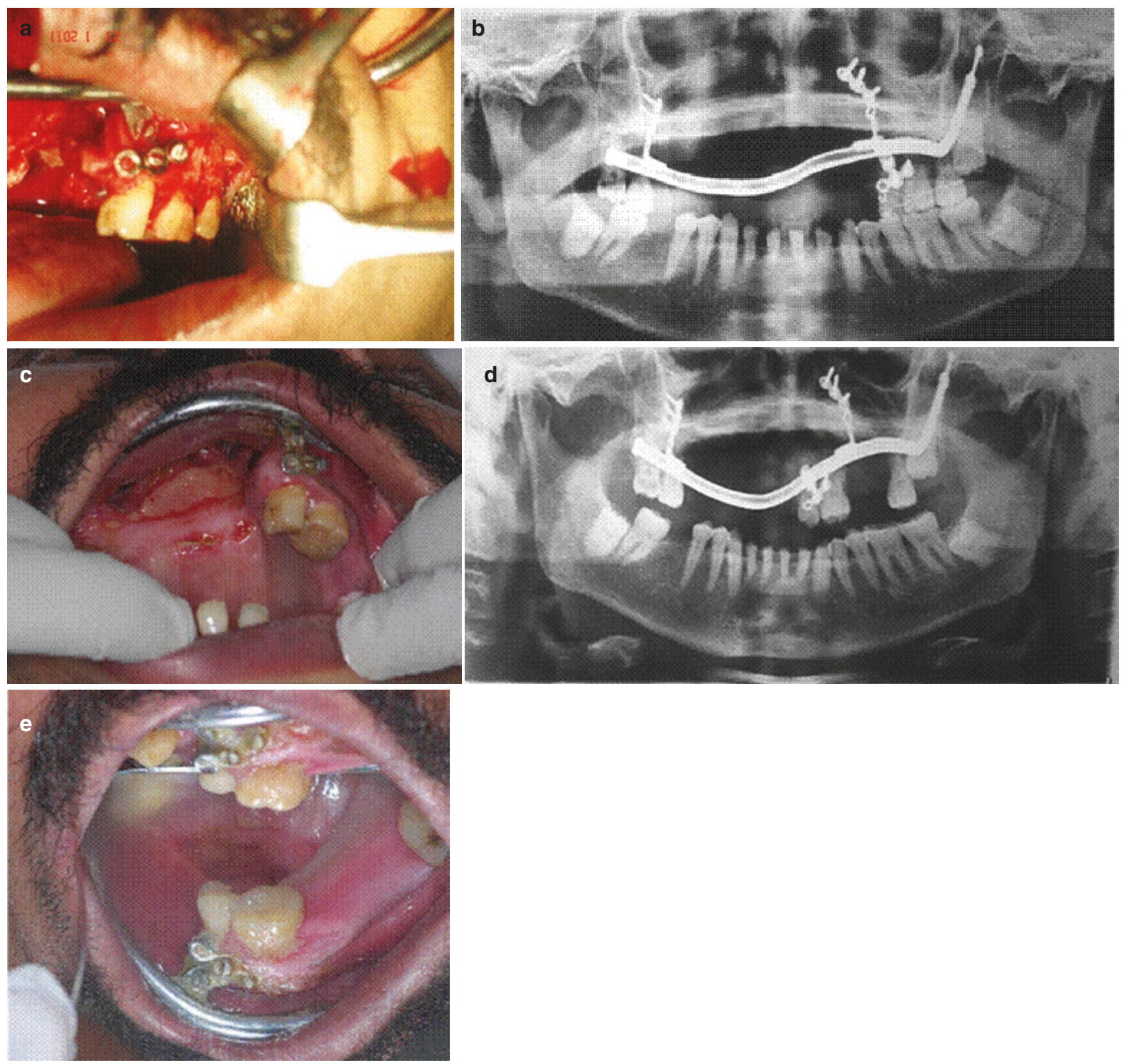

Fig. 87.24 (a) Arched bifocal regeneration with push ball device. (b)

across midline. (f, $\mathbf{g})$ Transport disc on docking and consolidation. (h, Bifocal push ball device in situ-latency period. (c, d) Transport disi) Post-consolidation and rehabilitation with complete denture traction in progress on same side. (e) Transport distraction in progress 

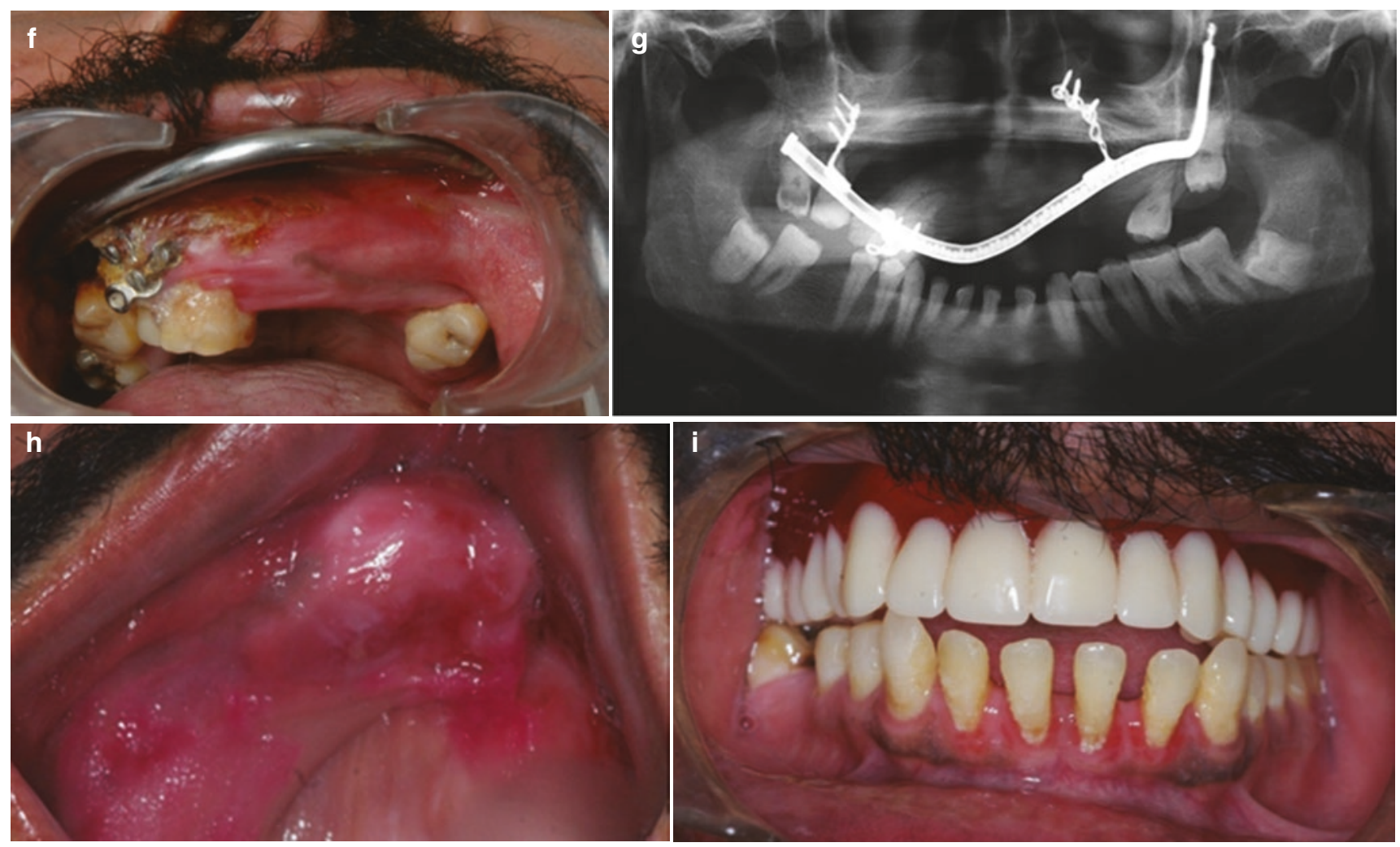

CAssociation of Oral and Maxillofacial Surgeons of India

Fig. 87.24 (continued)

The biological factors are the ones which we have very little control over, whereas the mechanical factors of vector control and bodily movement of transport segment across the midline can be successfully carried out by modifying the device (Table 87.3) [11, 12].

\subsubsection{Hypertrophic Regenerate}

This occurs when a single transport segment is designed to regenerate a lengthy defect, when the collagen fibers are overstretched with the central portion of the callus narrowing representing an hourglass appearance in the radiograph (Fig. 87.27). This phenomenon can also occur when the cross-sectional thickness of the transport segment is not adequate to recreate good volume of bone.

\subsubsection{Drifting of Teeth}

The teeth in the transport segment and RHBS tend to drift as distraction proceeds due to pull of transseptal fibers across the line of osteotomy. This problem could be overcome by applying a figure of eight wire to stabilize the teeth in each segment (Fig. 87.28a, b, c). 

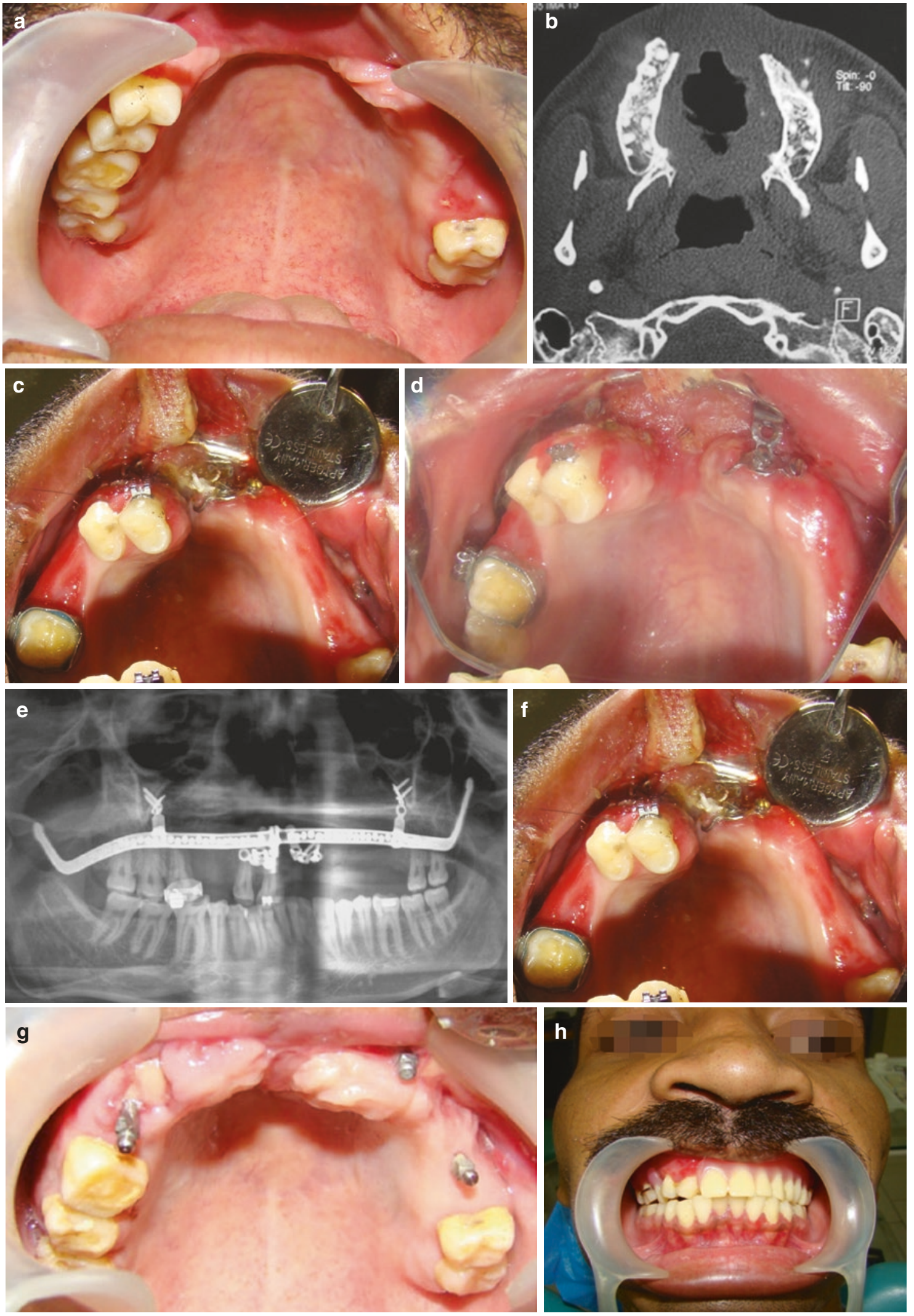

(OAssociation of Oral and Maxillofacial Surgeons of India

Fig. 87.25 (a) A case of continuity defect across midline following gunshot injury in a soldier. (b) CT image of case in $25 \mathrm{a}$. (c, d) Trifocal distraction in progress. (e) OPG view showing the trifocal distraction in progress. (f) Transport on docking and consolidation. (g, h) Dental rehabilitation using implants post-consolidation 

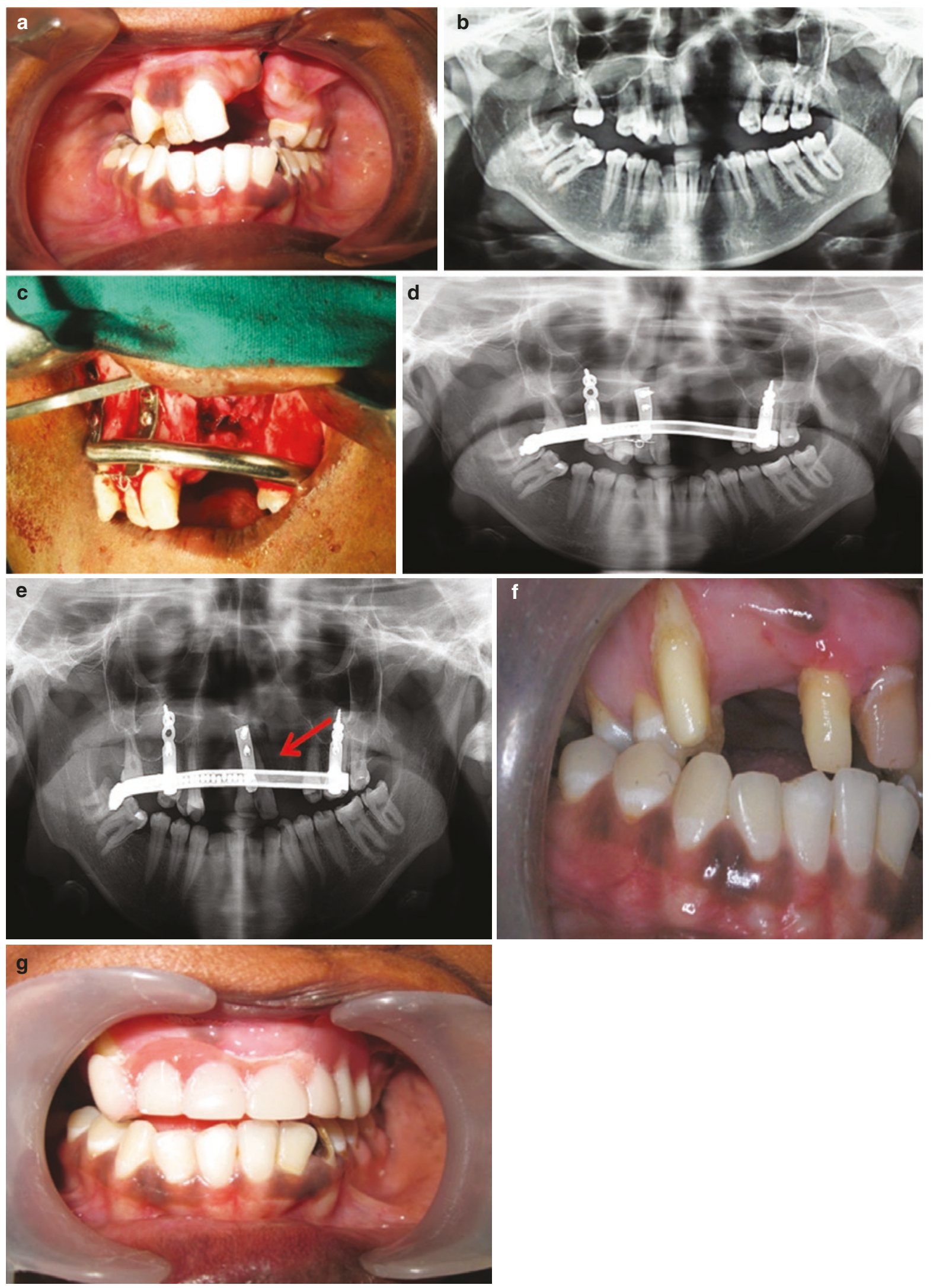

CAssociation of Oral and Maxillofacial Surgeons of India

Fig. 87.26 (a, b) A case of maxillary cleft alveolus. (c, d) Latency period of 5 days. (e) Docking of the transport disk on eighth post-op day. (f, g) Post-consolidation phase rehabilitation 


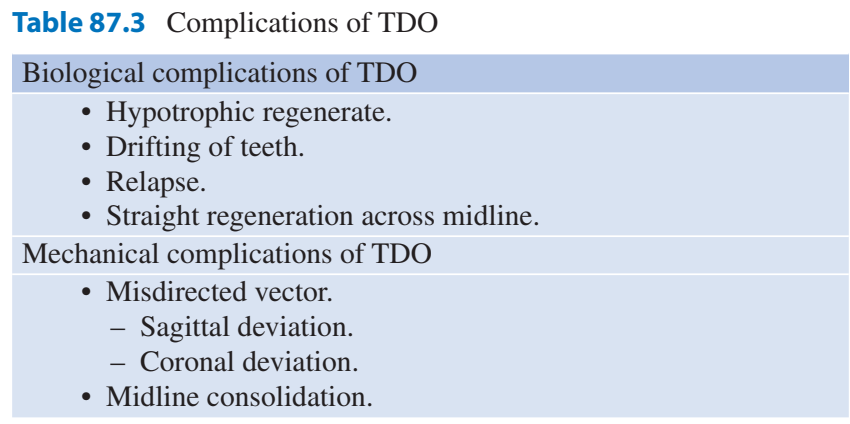

\subsubsection{Relapse}

Relapse of the new bone regenerate can occur resulting in contracture of the regenerate that could be avoided either by using an acrylic space maintainer or by placing a fixed partial denture immediately after the intended length of bone regenerate is formed across abutment teeth on either segment. It is a wise practice to retain the teeth in the transport disc for this purpose.

\subsubsection{Straight Regeneration}

Straight regeneration occurs while transporting the disc across the midline because the collagen fibers does not follow arc architecture of the defect in the midline; instead they get stretched in a straight direction, similar to an elastic band (Fig. 87.29a, b).

Misdirected vector in sagittal and coronal plane can occur when the guidance rod is not kept parallel to the occlusal plane. When such misdirection takes place, it can be allowed to proceed in the same vector until the intended length of bone regenerate is achieved, which could be corrected by callus molding before consolidation of the regenerate. The callus is molded by the rate and rhythm of the distraction and plating is done to achieve stability of the device. IMF is done to keep the occlusion intact on the contralateral side (Fig. 87.30a, b, c, d, e, f).

\subsubsection{Midline Consolidation}

The major limitation that we have with this modality of reconstruction is midline consolidation in both mandible and

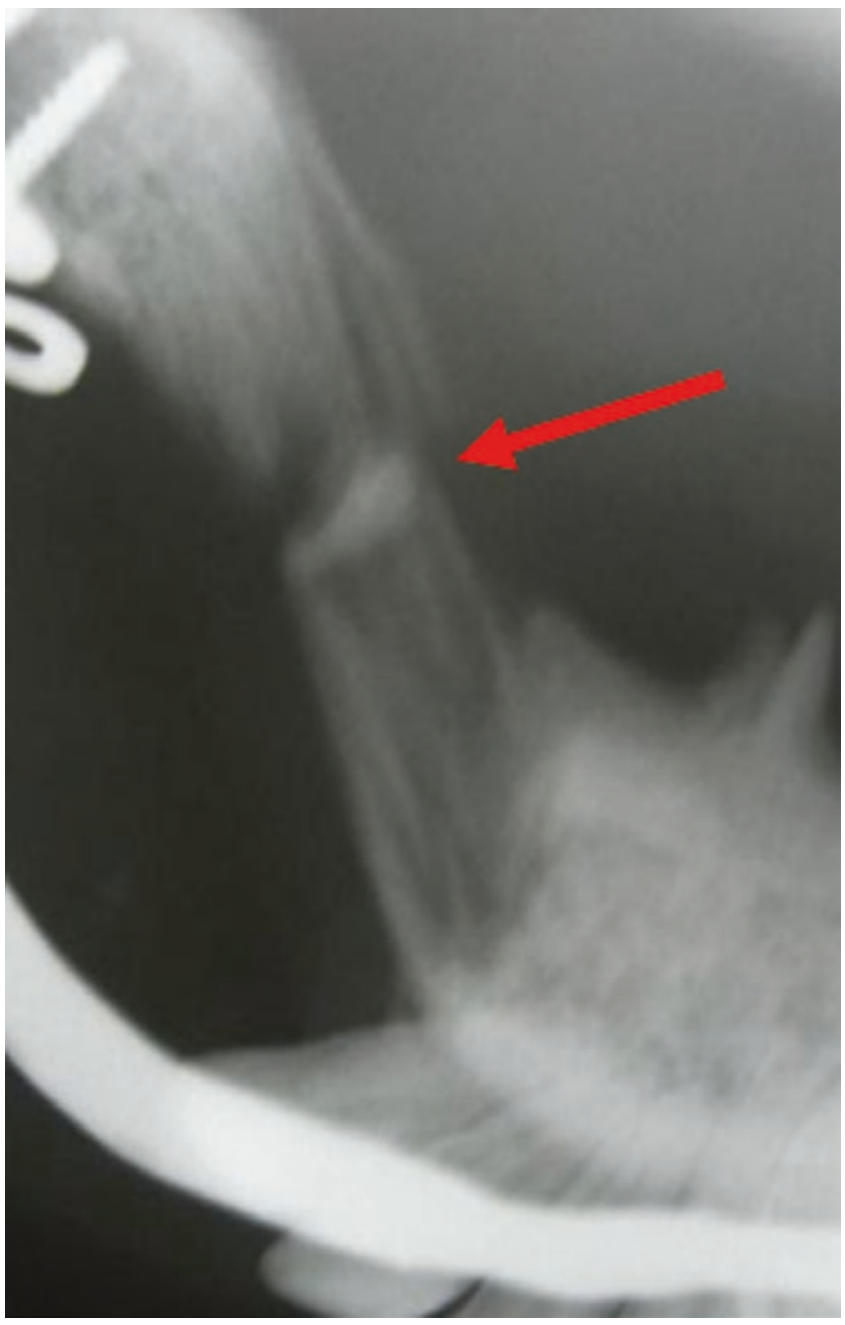

Fig. 87.27 Hourglass deformity

maxilla with arched regeneration. The transport segment freezes by the time it reaches a point lateral to midline on the opposite side. The concept of midline consolidation is that as the distraction proceeds beyond canine across the midline, the buccal cortex of the transport segment expresses greater movement than the lingual cortex for the same degree of rotation, as with the long and short arm of a clock suggesting lingual cortical tipping movement less than the required $1 \mathrm{~mm}$ per day. This results in lingual consolidation. This can be overcome by further re-distracting the transport segment after performing a lingual cortical osteotomy alone (Fig. 87.31a, b, c, d, e). 
Fig. 87.28 (a) Pull of the transseptal fibers. (b) Drifting of teeth. (c) Figure of 8 wiring
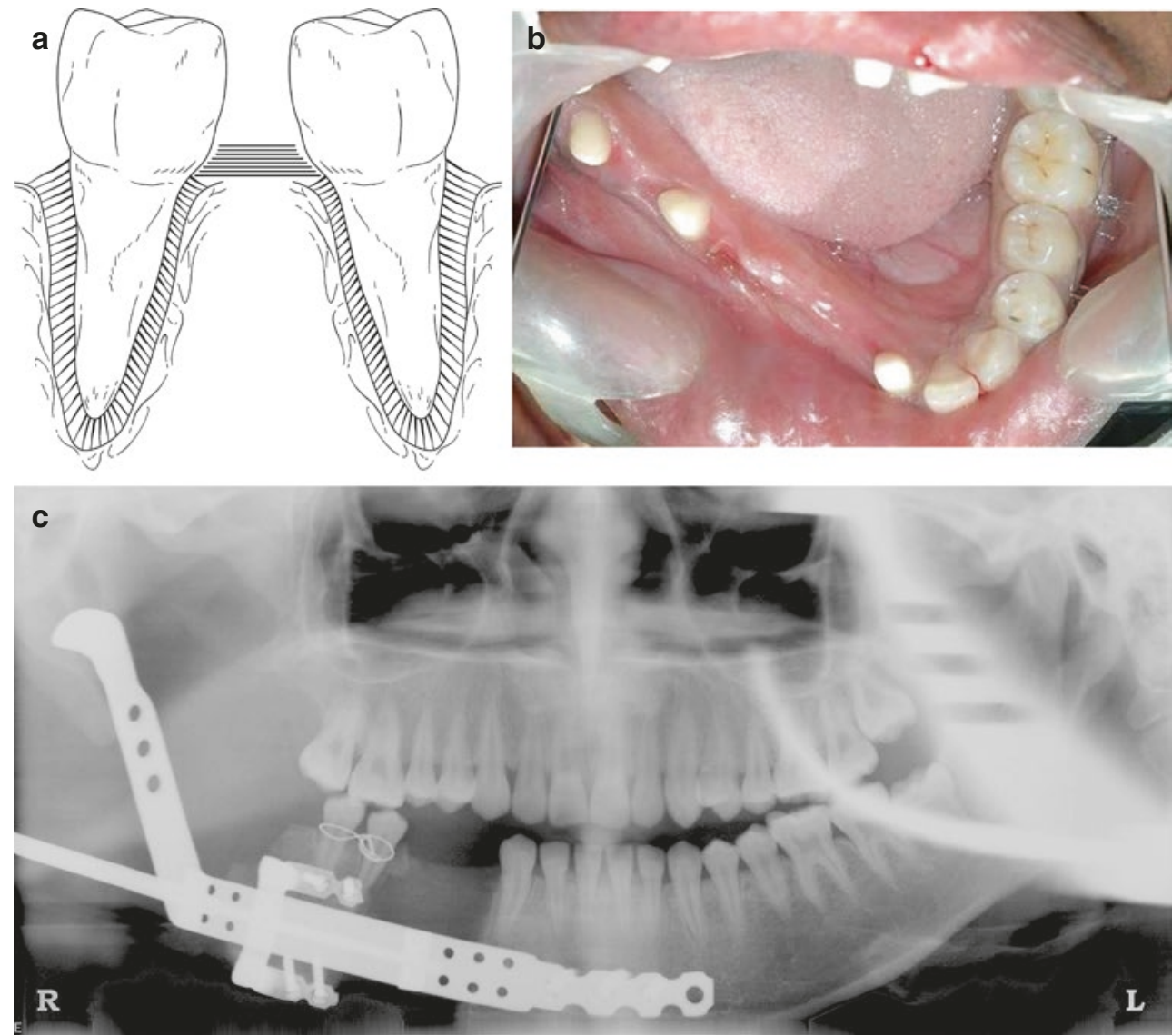

CAssociation of Oral and Maxillofacial Surgeons of India
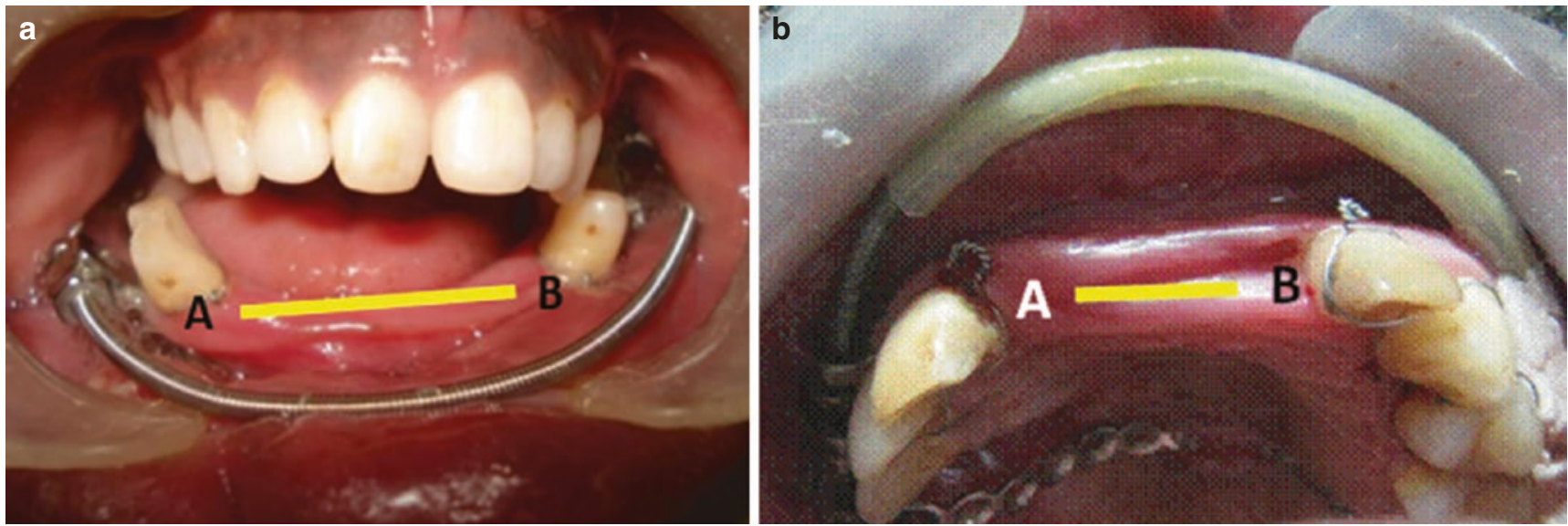

CAssociation of Oral and Maxillofacial Surgeons of India

Fig. 87.29 (a, b) Straight regeneration not conforming the arch form in mandible and maxilla 

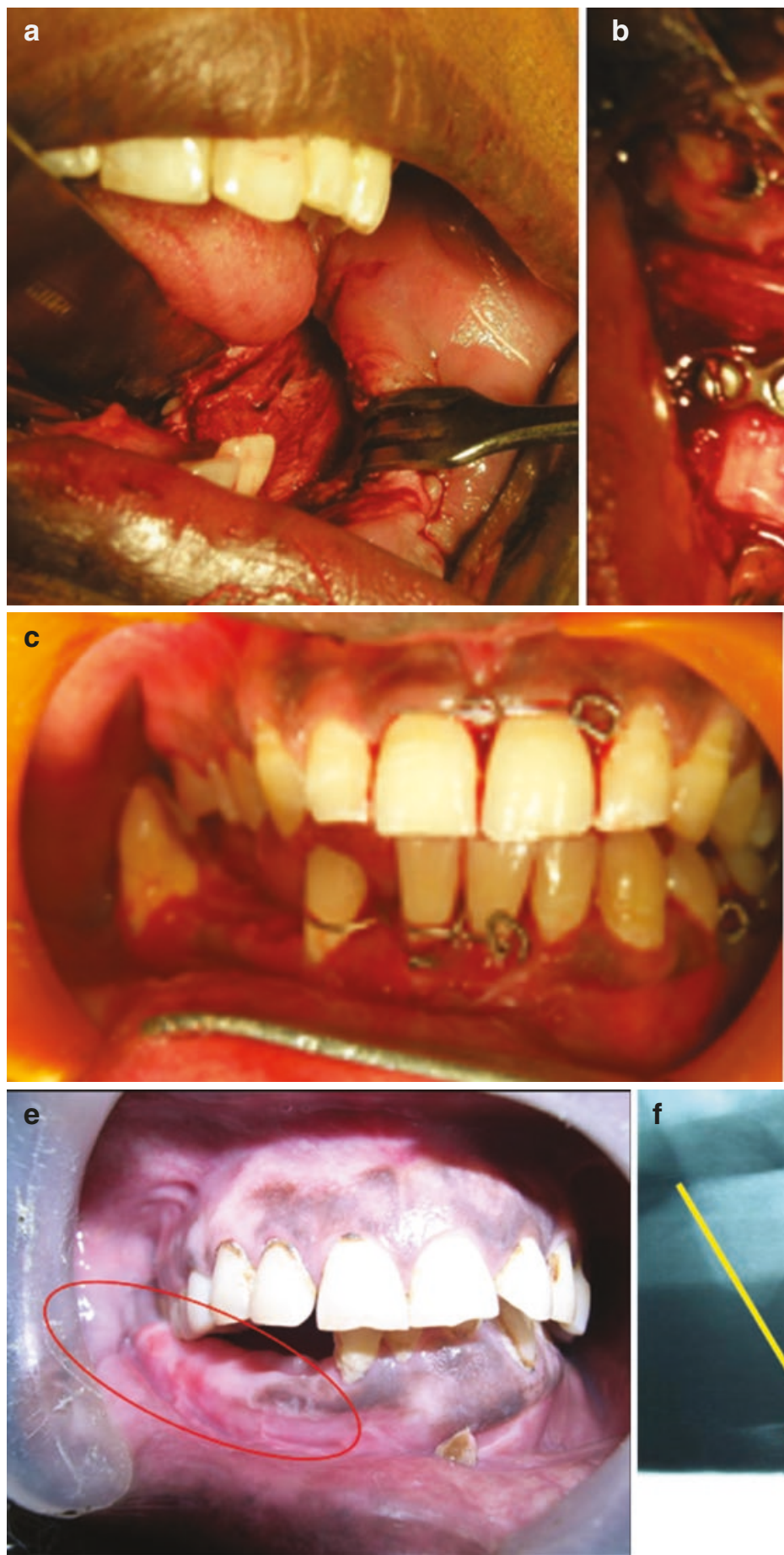

CAssociation of Oral and Maxillofacial Surgeons of India
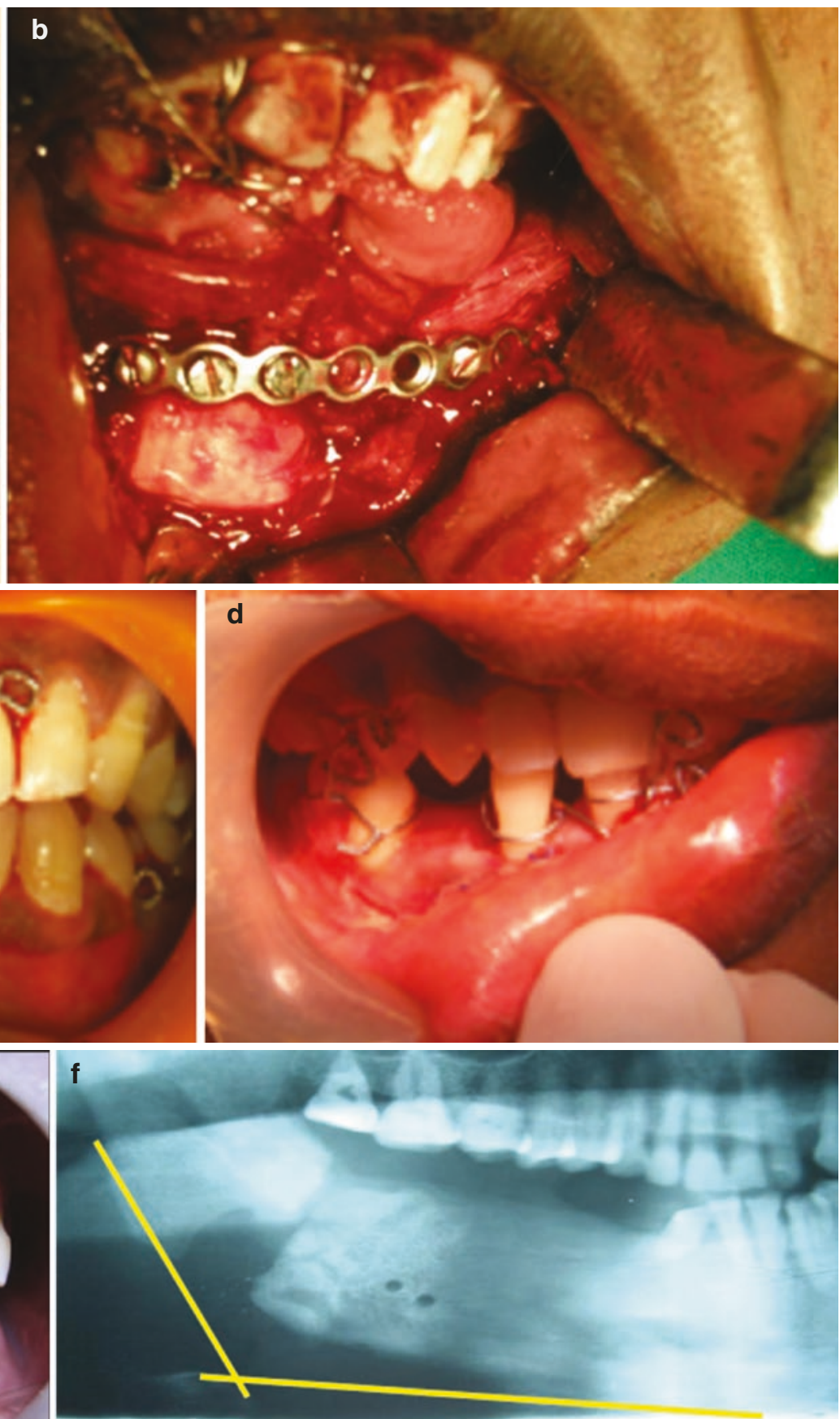

Fig. 87.30 (a, b) Callous molding and plating done for lingual deviation. (c, d) Callous molding and IMF done for buccal deviation. (e, f) Coronal deviation 


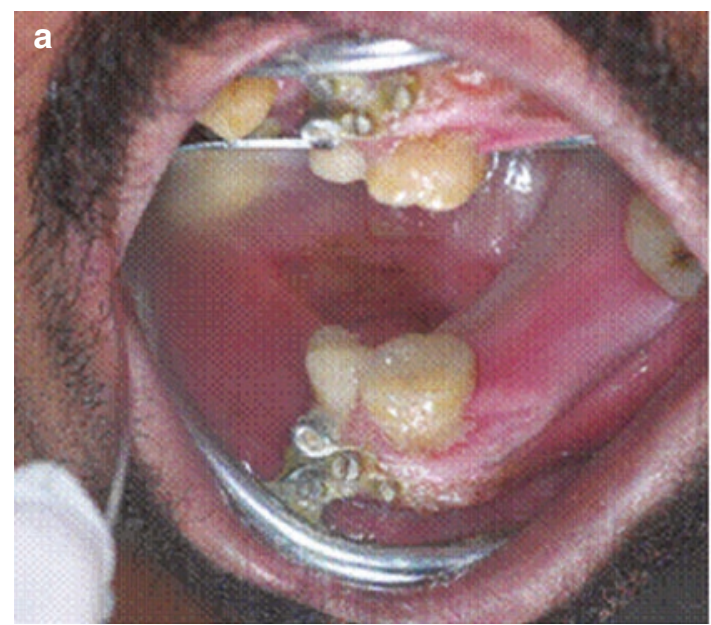

Maxilla
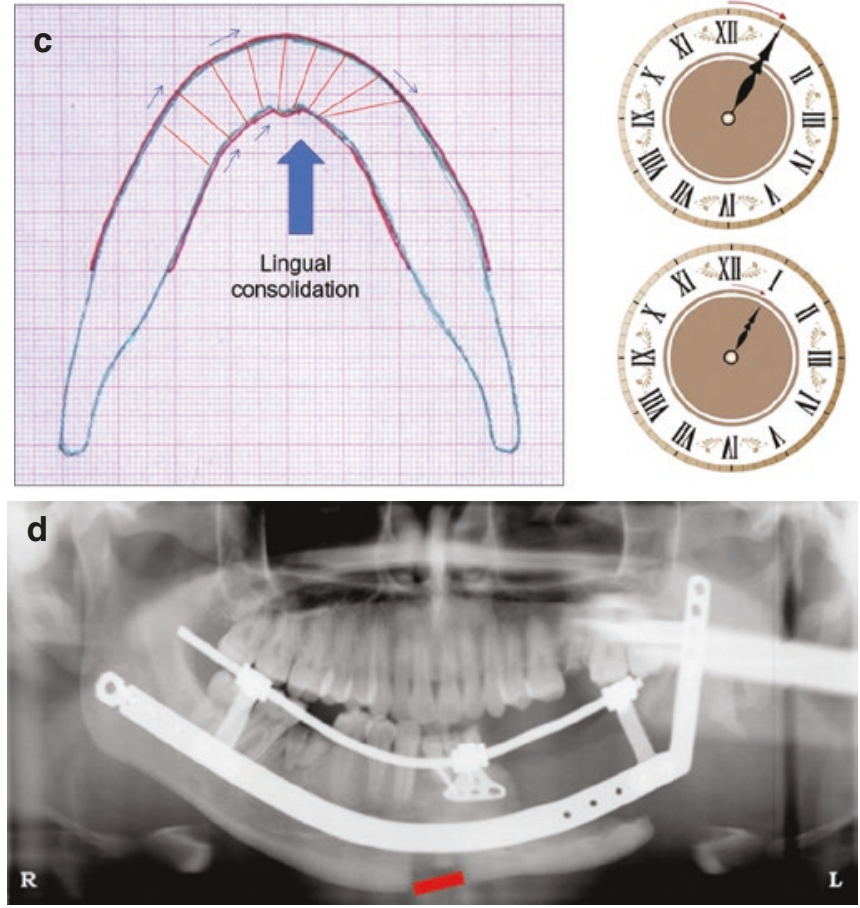

CAssociation of Oral and Maxillofacial Surgeons of India

Fig. 87.31 (a) Midline consolidation in maxilla (b) mandible. (c) Lingual consolidation as a result of lingual cortical tipping movement less than the required $1 \mathrm{~mm}$ per day (left) similar to the long and short hands of a clock. (d) Lingual consolidation (red line indicates the site

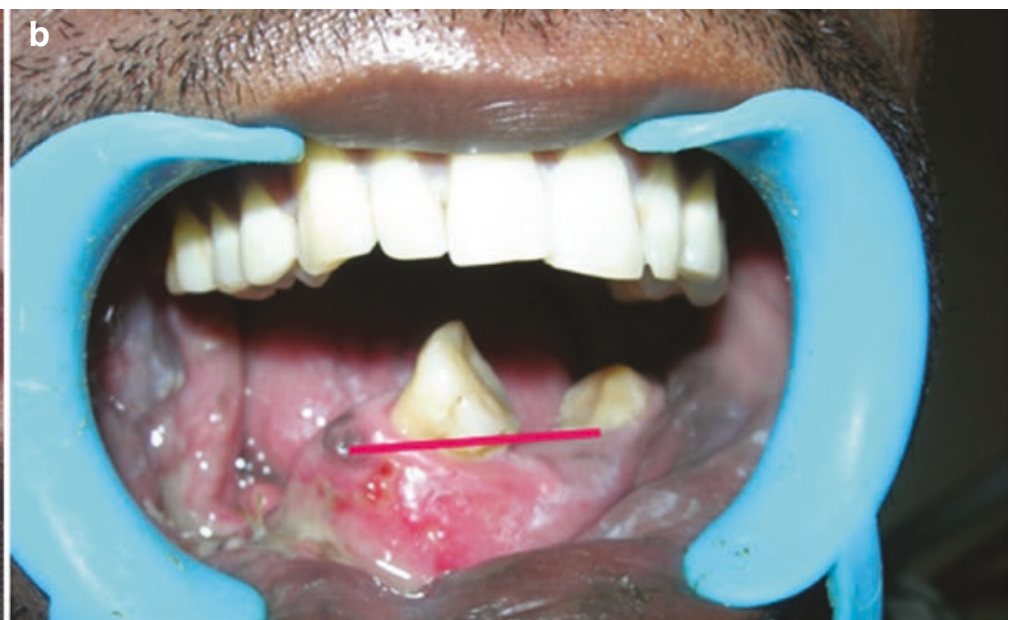

mandible

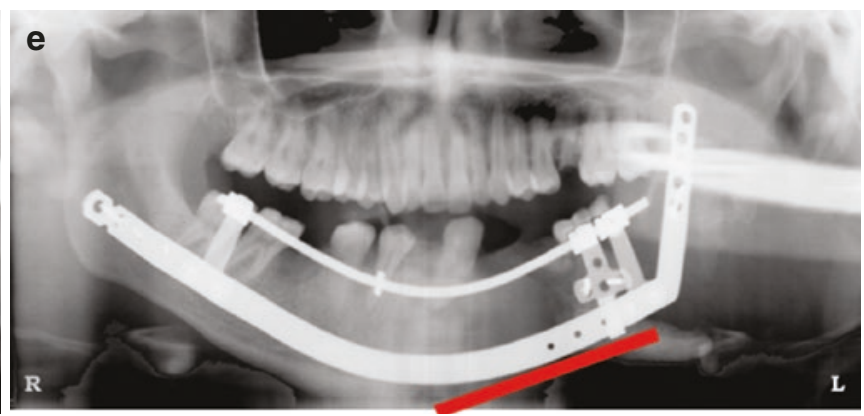

where callus will be formed after distraction). (e) Re-distraction after lingual cortical osteotomy (red line indicates the site where callus will be formed after distraction) 


\subsection{Role of Exogenous Growth Factors and Platelet-Rich Plasma (PRP) in TDO}

Studies have highlighted that the transforming growth factor-beta, basic fibroblast growth factor, and insulin-like growth factor I are the chief upregulated factors during TDO. These factors are present in the bony matrix, in the cytoplasm of the cells, in osteoblasts, and in a few mesenchymal cells. Distraction at faster rate shows stronger presence of the growth factors but clinically a poor regenerate. An optimum distraction rate, presence of the growth factors, and strict adherence to the biomechanical principles of DO remains the key to successful clinical outcome. Currently, external administration of the exogenous growth factors remains controversial and is a subject of further research, with evidences both for and against it. It may be concluded that the optimum TGF-beta1 is present during the distraction phase in vivo and its exogenous administration may not be recommended based on the evidences from future research. Injection of platelet-rich plasma (PRP) is found to have more favorable clinical outcome to enhance bone healing during distraction osteogenesis. PRP releases plateletderived growth factor and transforming factors (TGF-1 and TGF-2). Platelet-derived growth factors are the initial growth factors present in a wound and initiate connective tissue healing, bone regeneration, and repair. Plateletderived growth factors are a cost-effective and safe alternative to enhance mineralization of the distraction chamber.

In our experience with bioregulators, limited to PRP, we have found that injecting PRP into the site of new bone regenerate chamber after achieving the desired length through TDO, we can reduce the time of consolidation phase by one-third compared to consolidation phase without PRP. PRP has proved to hasten the mineralization of the regenerate and we can achieve the quality of bone that is usually expected in 6 weeks without PRP in 2 weeks' time itself, thus reducing the duration of treatment [13].

\subsection{Conclusion}

As we understand, microvascular surgery is not restricted to a particular specialty and is a technique that can be mastered by any surgeons of any specialty. However, it requires a steep learning curve, whereas bone transport doesn't require any additional training or equipment. It involves only the routine plate bending and fixing. So, to conclude, distraction osteogenesis is a continually evolving field of research and study and an aesthetically and functionally acceptable option for managing extensive maxillomandibular defects and those not amenable to conventional methods. It is akin to "old wine in new bottle" especially brewed to the taste of oral and maxillofacial surgeons, for it is the only contemporary modality of reconstruction that we maxillofacial surgeons can master ourselves and also one that we can call with pride as "our own (Refer Figs. 65.14, 65.15, and 65.17 for TMJ ankylosis cases where distraction osteogenesis has been used as a part of the overall treatment plan)."

Acknowledgments Figures 87.1 (a, b, c), 87.2 (a, b), 87.15c, 87.19, 87.22(a, b), 87.28 (a, b, c) are from Neelakandan RS, Bhargava D. Transport distraction osteogenesis for maxillomandibular reconstruction: current concepts and applications. J Maxillofac Oral Surg. 2012;11(3):291-299. Springer, https://www.ncbi.nlm.nih.gov/pmc/ articles/PMC3428445/.

Figure 87.23 (a, b, c, f) from Neelakandan RS, Mathew PC. Intraoral maxillary transport distraction: a casereport. J Oral Maxillofac Surg. 2009 Aug; 67(8):1751-5. PubMed PMID: 19615594. https://doi. org/10.1016/j.joms.2009.03.038. License Number 4613700616915. License date Jun 21, 2019. Licensed Content Publisher Elsevier.

Figure 87.25 (a, c, e) from https://www.ncbi.nlm.nih.gov/pmc/articles/PMC5328860/, https://doi.org/10.1007/s12663-015-0861-7; Rajkumar K, Neelakandan RS, Devadoss P, Bandyopadhyay TK. Reconstruction of a Post Traumatic Anterior Maxillary Defect by Transport Distraction Osteogenesis. J Maxillofac Oral Surg. 2017 Mar;16(1):118-122. Springer.

Figure 87.31 (d, e) from S. Neelakandan, R \& Bhargava, Darpan. (2011). Transport distraction along the mandibular midline. International journal of stomatology and occlusion medicine. 4. 123-126. https://doi.org/10.1007/ s12548-011-0018-3. (open access).

\section{References}

1. Neelakandan RS, Bhargava D. Transport distraction osteogenesis for Maxillomandibular reconstruction: current concepts and applications. J Maxillofac Oral Surg. 2012;11(3):291-9.

2. DeCoster TA, Simpson AH, Wood M, Li G. Biologic model of bone transport distraction osteogenesis and vascular response. J Orthop Res. 1999;17(2):238-45.

3. Kontogiorgos E, Elsalanty ME, Zapata U, Zakhary I, Nagy WW, Dechow PC, Opperman LA. Three-dimensional evaluation of mandibular bone regenerated by bone transport distraction osteogenesis. Calcif Tissue Int. 2011 Jul;89(1):43-52.

4. Garcia FL, Picado CH, Garcia SB. Histology of the regenerate and docking site in bone transport. Arch Orthop Trauma Surg. 2009;129(4):549-58.

5. Çakır-Özkan N, Eyibilen A, Özkan F, Gülbahar MY, Kabak YB. Immunohistochemicalanalysis of reconstructed sheep mandibles: transport distraction osteogenesis versus autogenous bone grafting. J Oral Maxillofac Surg 2011 Apr;69(4):1248-54.

6. Barber S, Carter L, Mannion C, Bates C. Distraction osteogenesis part 1: history and uses in the craniofacial region. Orthod Update. 2018;11(1):14.

7. Neelakandan RS, Mathew PC. Intraoral maxillary transport distraction: a case report. J Oral Maxillofac Surg. 2009;67(8):1751-5.

8. Rajkumar K, Neelakandan RS, Devadoss P, Bandyopadhyay TK. Reconstruction of a post traumatic anterior maxillary defect by transport distraction osteogenesis. J Maxillofac Oral Surg 2017 Mar;16(1):118-22. 
9. Cheung LK, Zhang Q, et al. Reconstruction of maxillectomy defect by transport distraction osteogenesis. Int J Oral Maxillofac Surg. 2003;32(2):515-20.

10. Neelakandan RS, Bhargava D. Transport distraction along the mandibular midline: conceptual analysis. J Stomat Occ Med. 2011;4:123-6.

11. Synder CC, Levine GA, Swanson HM, et al. Mandibular lengthening by gradual distraction: preliminary report. Plast Reconstr Surg. 1973;51:516.
12. Ruhaimi KA. Comparison of different distraction rates in mandible: an experimental investigation. Int J Oral Maxillofac Surg. 2001;30(1):216-20.

13. Chin M, Toth BA. Distraction osteogenesis in maxillofacial surgery using internal devices. Review of five cases. J Oral Maxillofac Surg. 1996;54:45-54.

Open Access This chapter is licensed under the terms of the Creative Commons Attribution 4.0 International License (http://creativecommons. $\mathrm{org} / \mathrm{licenses} / \mathrm{by} / 4.0 /$ ), which permits use, sharing, adaptation, distribution and reproduction in any medium or format, as long as you give appropriate credit to the original author(s) and the source, provide a link to the Creative Commons license and indicate if changes were made.

The images or other third party material in this chapter are included in the chapter's Creative Commons license, unless indicated otherwise in a credit line to the material. If material is not included in the chapter's Creative Commons license and your intended use is not permitted by statutory regulation or exceeds the permitted use, you will need to obtain permission directly from the copyright holder. 